\title{
HEAVY-LIFT FOR A NEW PARADIGM IN SPACE OPERATIONS
}

\author{
Bruce Morris \\ Exploration and Space Systems Manager \\ NASA Marshall Space Flight Center \\ Martin Burkey \\ Technical Writer, Schafer Corp. \\ Huntsville, Alabama
}

\begin{abstract}
NASA is developing an unprecedented heavy-lift capability to enable human exploration beyond low Earth orbit (LEO). This capability could also significantly enhance numerous other missions of scientific, national security, and commercial importance. That capability is currently configured as the Ares $V$ cargo launch vehicle. This capability will eclipse the capability the United States lost with the retirement of the Saturn V. It is capable of launching roughly 53 percent more payload mass to trans lunar injection (TLI) and 30 percent more payload mass to LEO than its Apollo Program predecessor. Ares V is a major element of NASA's Constellation Program, which also includes the Ares I crew launch vehicle (CLV), Orion crew exploration vehicle (CEV), and a lunar lander for crew and cargo. As currently configured, Ares $V$ will be capable of launching 413,800 pounds (187.7 $\mathrm{mT})$ to $\mathrm{LEO}, 138,500$ pounds $(63 \mathrm{mT})$ direct to the Moon or 156,700 pounds $(71.1 \mathrm{mT})$ in its dual-launch architecture role with Ares I. Its 33-foot $(10 \mathrm{~m})$ shroud provides unprecedented payload volume. Assessment of astronomy and planetary science payload requirements since spring 2008 has indicated that a Saturn V-class heavy-lift vehicle has the potential to support a range of payloads and missions. This vehicle configuration enables some missions previously considered difficult or impossible and enhances many others. Collaborative design/architecture inputs, exchanges, and analyses have already begun between scientists and payload developers. This early dialogue between NASA engineers and payload designers allows both communities to shape their designs and operational concepts to be mutually supportive to the extent possible with the least financial impact. This paper provides an overview of the capabilities of a heavy-lift vehicle to launch payloads with increased mass and/or volume and reduce technical and cost risk in both design and operations.
\end{abstract}

\section{Introduction}

he field of space operations is a broad subject, bounded generally by the operation desired and resources

available. The choice of launch vehicle, however, affects almost every other aspect of operation. At its most basic, it translates into mass and volume available for payload. The development of a heavy-lift capability for NASA's Constellation Program architecture changes the rules so dramatically that it is already prompting the payload and user communities to re-think their usual assumptions. The major components of the Constellation Program are shown in figure 1. 


\section{Our Exploration Fleet What Will the Vehicles Look Like?}

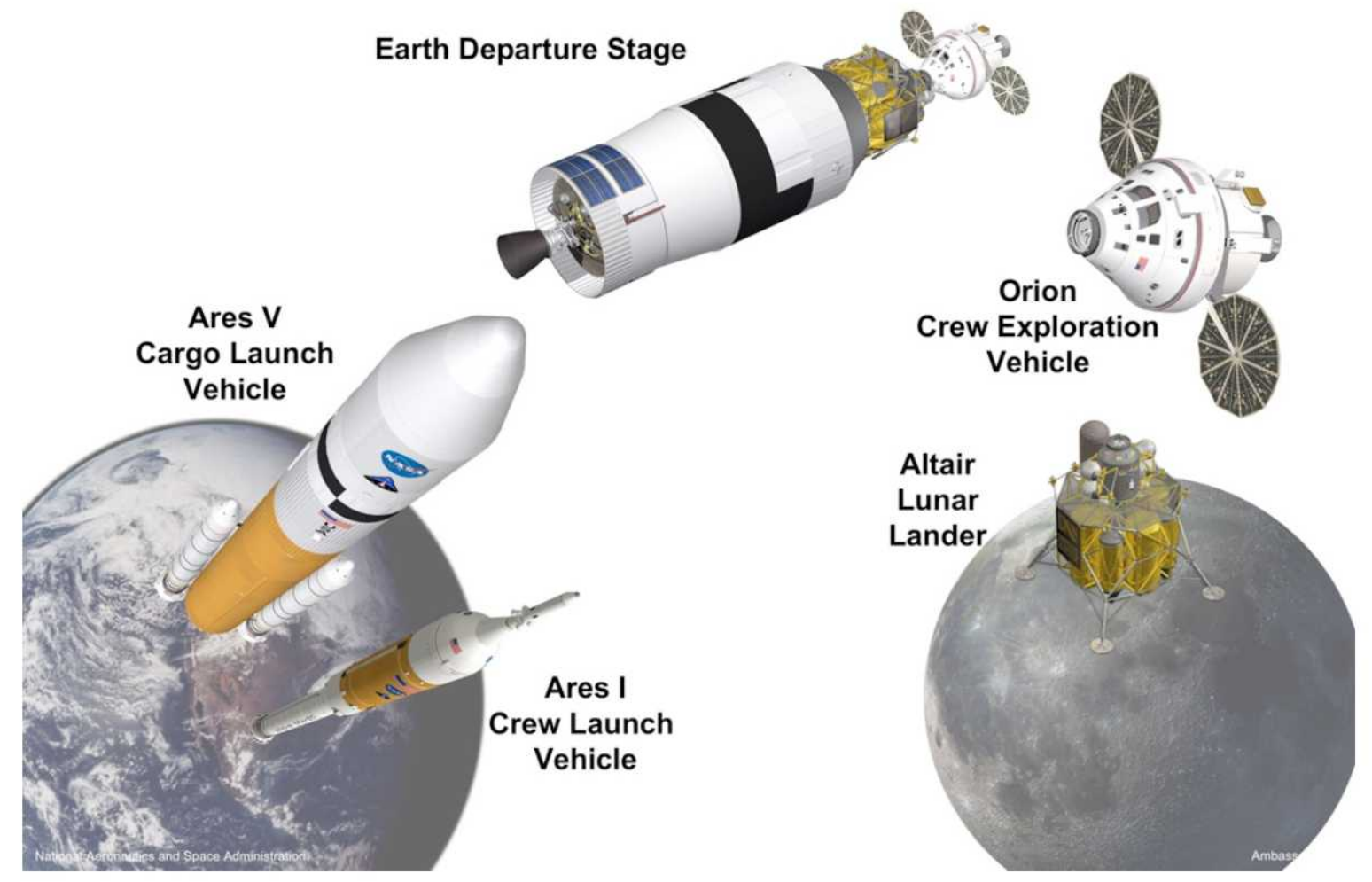

Figure 1 - Constellation architecture components

\section{Ares V in Context}

Constellation emerged out of the intense reexamination of the U.S. civil space program after the Space Shuttle Columbia accident. Acknowledging the aging shuttle fleet and recognizing the need for new goals for NASA, the agency was directed to retire the shuttle fleet, develop its successor, complete the International Space Station, and develop the means to resume human exploration beyond LEO, beginning with the Moon. To meet those goals, NASA conducted the Exploration Systems Architecture Study (ESAS). The architecture that emerged consisted of the Orion crew spacecraft, a lunar lander, the Ares I crew launch vehicle, and a heavy-lift capability dubbed Ares V. In an effort to minimize both development and operational costs, the Ares vehicles are designed to use proven technologies, components, and infrastructure from the Saturn, Space Shuttle and contemporary launch vehicle programs. For the same reasons, the Ares vehicles are designed to share common components and infrastructure where possible. Together, they are designed to provide safe, reliable, flexible, cost-effective transportation to low Earth orbit and beyond.

Ares I is designed to launch the Orion crew exploration vehicle with crews of up to four into LEO for missions to ISS or the Moon. The Ares I five-segment solid fuel first stage is based on the Shuttle four-segment solid rocket booster. The new upper stage is powered by the J-2X liquid fuel engine, an evolution of the proven J-2 engine that powered the Saturn I and Saturn V upper stages. The first payload for the Ares V heavy lifter is the Earth departure stage (EDS) and lunar lander. The current Ares V first stage configuration consists of a 33-foot core stage powered by six commercial Pratt \& Whitney RS-68 engines and a pair of 51/2 - segment solid propellant boosters similar to the Ares I first stage. Upper stage propulsion is provided by the EDS, which is also 33 feet in diameter and powered by a J-2X engine that is similar to the Ares I engine but modified for on-orbit loiter and the TLI operation. Atop the 
EDS are a payload adapter and a 33-foot-diameter payload shroud totally encapsulating the lander. The latest Ares V configuration is illustrated in figure 2 .

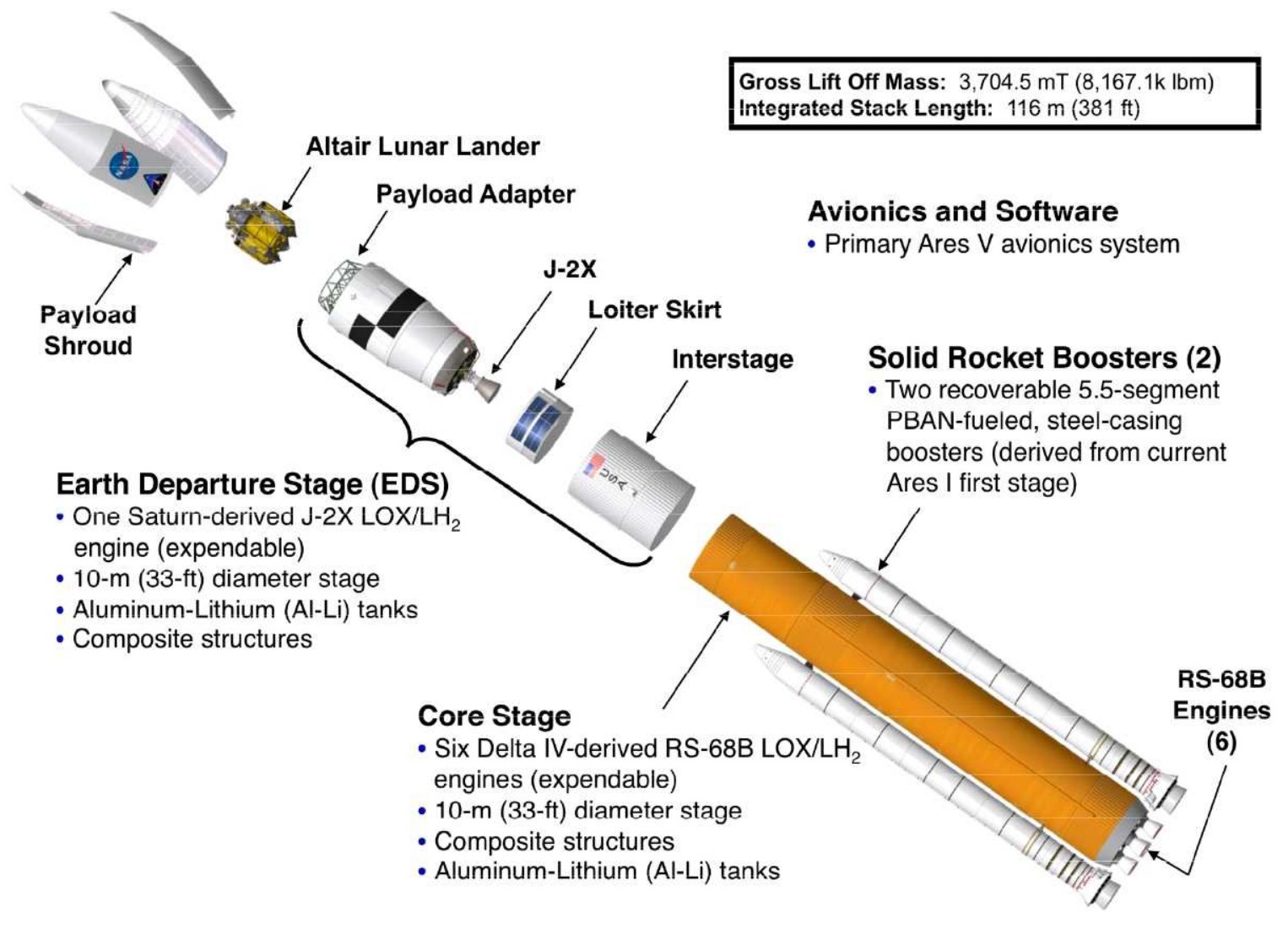

Figure 2 - Expanded view of the current Ares V reference configuration

In order to carry out the National Space Policy directive to replace the Space Shuttle and complete the ISS, the Constellation development plan focuses on developing the Ares I and making it operational by 2015 . Ares V was planned to begin development beyond 2010 to support human lunar exploration in the 2020 time frame.

The Constellation Architecture Requirements Document (CARD) provides the mass requirements for both the Lunar Sortie (crewed) and Lunar Cargo Design Reference Missions (DRMs).

For the sortie mission, the CARD specifies an Orion control mass of $20.2 \mathrm{t}(44,500 \mathrm{lbm})$ and a Lunar Lander control mass of $45 \mathrm{t}(99,208 \mathrm{lbm})$. The total TLI payload requirement is $66.9 \mathrm{t}(147,575 \mathrm{lbm})$. The sortie mission assumes a LEO destination orbit of $242 \mathrm{~km}(130 \mathrm{nmi})$ at 29 degrees inclination. The CARD loiter duration is not specified but has continued to evolve with program and project trades from 95 days to 14 days. For the LCCR trades, it was further reduced to 4 days. The TLI maneuver begins at a minimum $185 \mathrm{~km}$ (100 nmi) altitude with a Delta Velocity $(\Delta \mathrm{V})$ requirement of $3,175 \mathrm{~m} / \mathrm{s}(10,417 \mathrm{f} / \mathrm{s})$ plus gravity loss.

For the cargo mission, the CARD specifies a Cargo Lander control mass of $53.6 \mathrm{t}(118,168 \mathrm{lbm})$ and a total TLI payload mass of $54.6 \mathrm{t}(120,372 \mathrm{lbm})$. The cargo mission assumes a phasing orbit Earth-To-Orbit (ETO) destination. Because Orion is not part of the cargo mission operations concept, a loiter requirement is unnecessary; however, a few orbits in LEO is anticipated to allow for system checkout prior to the TLI burn. It is worth noting that the Saturn V TLI payload capability was 48.6 t (107,445 lbm) for the Apollo 17 mission. 
The CARD also imposes additional requirements on the Ares V, such as the use of the five-segment solid rocket booster and five RS-68B engines in the Core Stage and the Mars mission mass requirements. The CARD requirements are shown in figure 3.

\begin{tabular}{|c|c|c|c|}
\hline \multicolumn{4}{|c|}{ Lunar Sortie Mission } \\
\hline CARD Requirement & Mass (t) & Mass $\left(\mathrm{Ib}_{\mathrm{m}}\right)$ & Derived Performance Rqt. \\
\hline Orion [CA4139] & 20.2 & 44,500 & \\
\hline Crewed Lander [CA0836] & 45.0 & 99,208 & \\
\hline Total TLI [CA0848] & 66.9 & 147,575 & Derived $\mathrm{TLI}>66.9 \mathrm{t}$ \\
\hline & 45.0 & 99,208 & Derived ETO $>45.0 \mathrm{t}$ \\
\hline \multicolumn{4}{|c|}{ Lunar Cargo Mission } \\
\hline CARD Requirement & Mass $(t)$ & Mass $\left(\mathrm{Ib}_{\mathrm{m}}\right)$ & Derived Performance Rqt. \\
\hline Cargo Lander [CA5231] & 53.6 & 118,168 & \\
\hline Total TLI [CA0847] & 54.6 & 120,372 & Derived $\mathrm{TLI}>54.6 \mathrm{t}$ \\
\hline Total ETO Goal [CA0847] & 54.6 & 120,372 & Derived ETO $>54.6 \mathrm{t}$ \\
\hline
\end{tabular}

Figure 3 - Ares $\mathrm{V}$ performance requirements for lunar crew and lunar cargo missions

\section{Refining the Heavy-lift Configuration}

NASA's heavy-lift vehicle remains in a concept definition stage, while NASA focuses development on the Ares I. The Ares $\mathrm{V}$ design has evolved through hundreds of configurations, trading factors such as engines, engine count, number of stages, stage diameters, propellants, structural materials and more. The current point of departure (POD) configuration, serving as the basis for subsequent analyses, was approved during the Lunar Capabilities Concept Review in 2008. The LCCR trade space focused on six vehicle concepts. Those concepts are illustrated in figure 4.

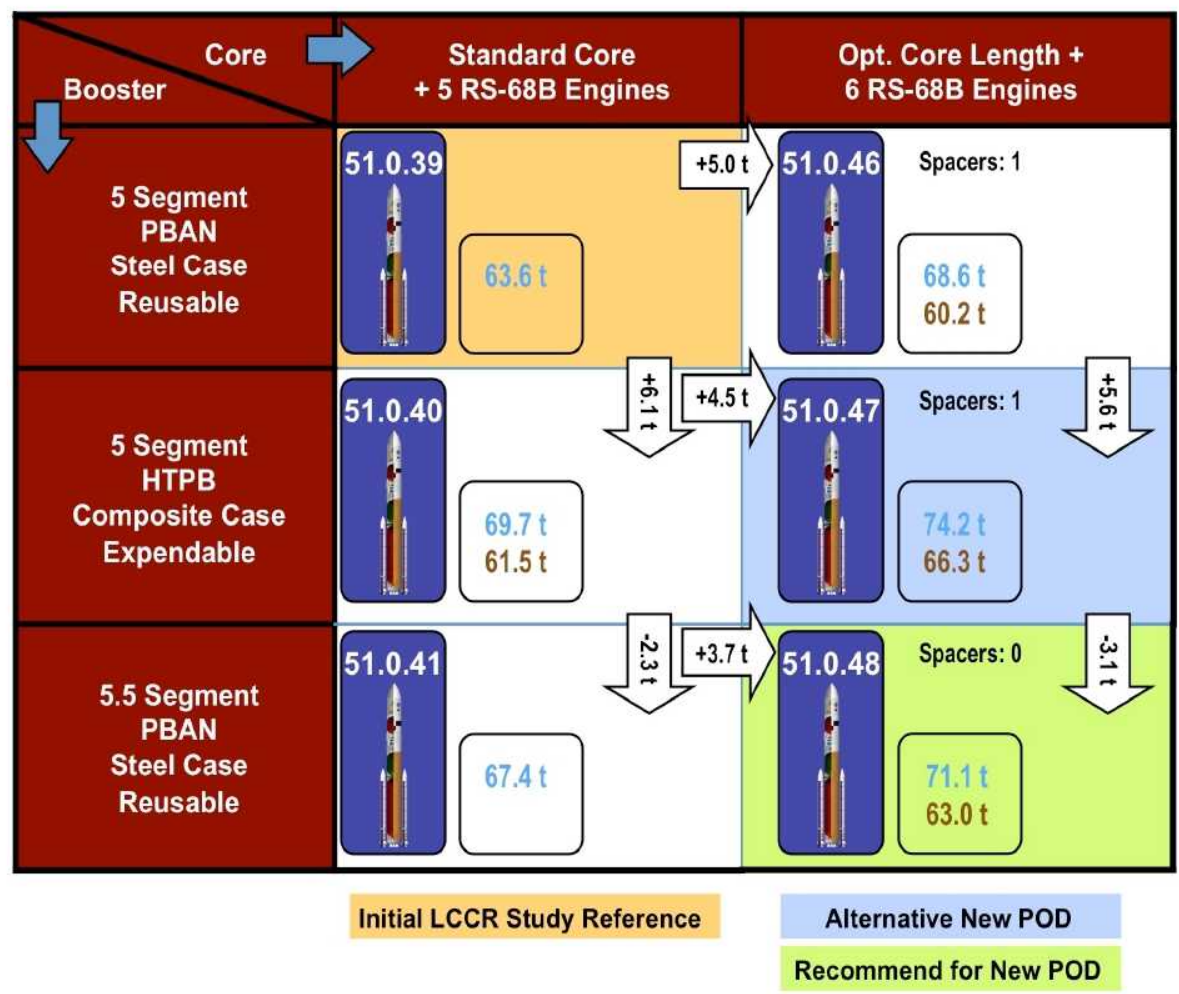

\begin{tabular}{|c|}
\hline Common Design Features \\
\hline $\begin{array}{l}\text { Composite Dry Structures } \\
\text { for Core Stage, EDS \& } \\
\text { Shroud }\end{array}$ \\
\hline $\begin{array}{l}\text { Metallic Cryo Tanks for Core } \\
\text { Stage \& EDS }\end{array}$ \\
\hline $\begin{array}{l}\text { RS-68B Performance: } \\
\text { Isp=414.2 s } \\
\text { Thrust = 797K lbf @ vac }\end{array}$ \\
\hline $\begin{array}{l}\text { J-2X Performance: } \\
\text { Isp }=448.0 \mathrm{~s} \\
\text { Thrust }=294 \mathrm{~K} \text { lbf @ vac }\end{array}$ \\
\hline $\begin{array}{l}\text { Shroud Dimensions: } \\
\text { Barrel Dia. }=10 \mathrm{~m} \\
\text { Usable Dia. }=8.8 \mathrm{~m} \\
\text { Barrel Length }=9.7 \mathrm{~m}\end{array}$ \\
\hline $\begin{array}{l}\text { 1.5 Launch TLI Capability } \\
\text { Cargo TLI Capability }\end{array}$ \\
\hline
\end{tabular}


The design chosen as the new POD concept at the LCCR, designated 51.0.48, was characterized by: the extended core stage and the 5.5-segment, PBAN, steel booster. This POD vehicle will support up to $71.1 \mathrm{t}(156,700 \mathrm{lbm})$ of payload to TLI for crewed missions. This concept was maintained in the LCCR trade space because it provides a competitive level of TLI performance. It also does not require significant funding for technology development nor does it incur the largest production and Design, Development, Test, and Evaluation (DDT\&E) costs. While it provides architecture closure with additional margin, it does not fully meet the desired TLI payload goal of $75 \mathrm{t}$ $(165,300 \mathrm{lbm})$. The Constellation Program also approved continuing to carry the 51.0.47 concept as an option for continued study, despite its higher technical complexity, because it provided additional performance margin. Since LCCR, the reference concept has served as the basis for further design exercises in an effort to improve performance, enhance operability, and understand mission impacts.

\section{Heavy-lift Utilization Potential and Outreach}

Several independent panels since Apollo have pointed out the need for a national heavy-lift launch capability for human and robotic exploration and science, national security, and commercial endeavors. NASA's current heavy-lift design restores U.S. heavy-lift capability and surpasses the 1960 s-era Saturn V by a large margin in both mass and volume. This capability is viewed by NASA as a national asset for exploration, science, national security, and commercial payloads. The current heavy-lift reference concept will offer unprecedented performance to all known orbits both in terms of mass and volume. Compared to current systems, it will offer approximately five times the mass and volume to most orbits and locations. This should allow prospective mission planners to build robust payloads with margins that are three to five times today's industry norm.

The thrust at take-off will be approximately $40 \%$ more than any other vehicle ever built. This will likely create induced environments outside the normal range of payload planners. However, it is likely that the unprecedented mass and volume afforded will allow for material choices and induced environment mitigation not normally considered possible on existing launch vehicles. The NASA heavy-lift team is already reaching out to the payload community 2-3 years before the Systems Requirements Review (SRR) in order to better understand the potential limitations and/or additional requirements that could be added to a heavy-lift vehicle from the mission planning community. If a viable mission is determined and added to the heavy lifter as a design case, tradeoffs will be conducted to determine if other mission design requirements can be included in the system.

Figure 5 shows performance for selected missions using an earlier study configuration of the Ares $\mathrm{V}$ designated 51.00.39. The current reference configuration - effectively the addition of an extra half-segment to the booster and a sixth core stage engine - is expected to have slightly higher performance. As indicated, this capability can deliver tremendous payloads to a wide variety of orbital parameters. While having the capability of delivering over 57 metric tons of lunar cargo \& over 48 metric tons of Mars cargo, it can also provide approximately 69.5 metric tons to GTO and 35 metric tons to GEO. This is approximately 6 times that of any currently manufactured launch vehicle. The ground rules assumptions for these calculations are: no gravity assists, interplanetary trip times based on Hohmann transfers, payload mass estimates comprise spacecraft, payload adapter and mission peculiar hardware, two-engine Centaur for kick stage. 


\begin{tabular}{|c|c|c|c|c|c|}
\hline \multirow[t]{2}{*}{ Mission Profile } & \multirow[t]{2}{*}{ Target } & \multicolumn{2}{|c|}{ Constellation POD Shroud } & \multicolumn{2}{|c|}{ Extended Shroud } \\
\hline & & Payload (Ibm) & Payload (mt) & Payload (lbm) & Payload (mt) \\
\hline 1) LEO (@29 inclination) & $241 \times 241 \mathrm{~km}$ & 315,000 & 143 & 313,000 & 142 \\
\hline 2) GEO & $\begin{array}{c}\text { Transfer DV } \\
14,100 \mathrm{ft} / \mathrm{s}\end{array}$ & 77,000 & 35 & 76,000 & 34.5 \\
\hline $\begin{array}{l}\text { 3) Cargo Lunar } \\
\text { Outpost (TLI Direct), Reference }\end{array}$ & $\mathrm{C} 3$ of $-1.8 \mathrm{~km}^{2} / \mathrm{s}^{2}$ & 126,000 & 57 & 125,000 & 57 \\
\hline $\begin{array}{l}\text { 4) Sun-Earth L2 } \\
\text { Transfer Orbit } \\
\text { Injection }\end{array}$ & $\mathrm{C} 3$ of $-0.7 \mathrm{~km}^{2} / \mathrm{s}^{2}$ & 124.000 & 56.5 & 123,000 & 56 \\
\hline $\begin{array}{l}\text { 5) Earth-Moon L2 Transfer } \\
\text { Orbit } \\
\text { Injection }\end{array}$ & $\mathrm{C} 3$ of $-1.7 \mathrm{~km}^{2} / \mathrm{s}^{2}$ & 126,000 & 57.0 & 125,000 & 57 \\
\hline 6) GTO Injection & $\begin{array}{c}\text { Transfer DV } \\
8,200 \mathrm{ft} / \mathrm{s}\end{array}$ & 153,000 & 69.5 & 152,000 & 69 \\
\hline $\begin{array}{l}\text { 7) Mars Cargo (TMI } \\
\text { Direct) }\end{array}$ & $\mathrm{C} 3$ of $9 \mathrm{~km}^{2} / \mathrm{s}^{2}$ & 106,000 & 48 & 105,000 & 48 \\
\hline
\end{tabular}

Figure 5 - Ares V performance for selected missions.

This potentially opens up direct missions to the outer planets that are currently only achievable using indirect flights with gravity assist trajectories. An Ares V with an upper stage could perform these missions using direct flights with shorter interplanetary transfer times, which enables extensive in-situ investigations and potentially sample return. Another unique aspect of this configuration is the large $8.8-\mathrm{m}$ interior diameter of its fairing. This enables the launch of very large monolithic mirrors, arrays of precision flying mirrors, or extremely large deployable telescopes. Figure 6 illustrates the Ares V shroud's enormous volume available for various missions. Both its baseline shroud and a notional extended shroud are shown. The reference Ares shroud has a usable volume of 860 $\mathrm{m} 3$, which is more than three times the volume of the Delta IV fairing. For larger payloads, the cylindrical portion of the reference shroud could be extended by $9 \mathrm{~m}$, to provide usable volume of 1,410 cubic meters.

The space inside the reference configuration shroud has enough usable volume to launch the volumetric equivalent of approximately 10 Apollo Lunar Excursion Modules (LEMs) or approximately 5 Hubble Space Telescopes. This mass and volume capability to LEO enables a host of new scientific and observation platforms, such as telescopes, satellites, and planetary and solar missions, as well as being able to provide the lift for future large in-space infrastructure missions, such as space-based power and mining, Earth asteroid defense, propellant depots, etc.

Multiple shroud options for the Ares V have been analyzed to identify their impact on performance. While larger shrouds allow for increased usable volume, the mass of these large structures has a net negative effect on payload mass. In addition, the height of the vehicle is increased accordingly. This may cause existing facilities to be modified in order to accommodate the launch vehicle. While individual missions have unique requirements, one thing remains a constant - the Ares V will launch more mass with more volume to anywhere than any launch vehicle currently being manufactured. Some sample shrouds past and present are shown in Figure 7. 

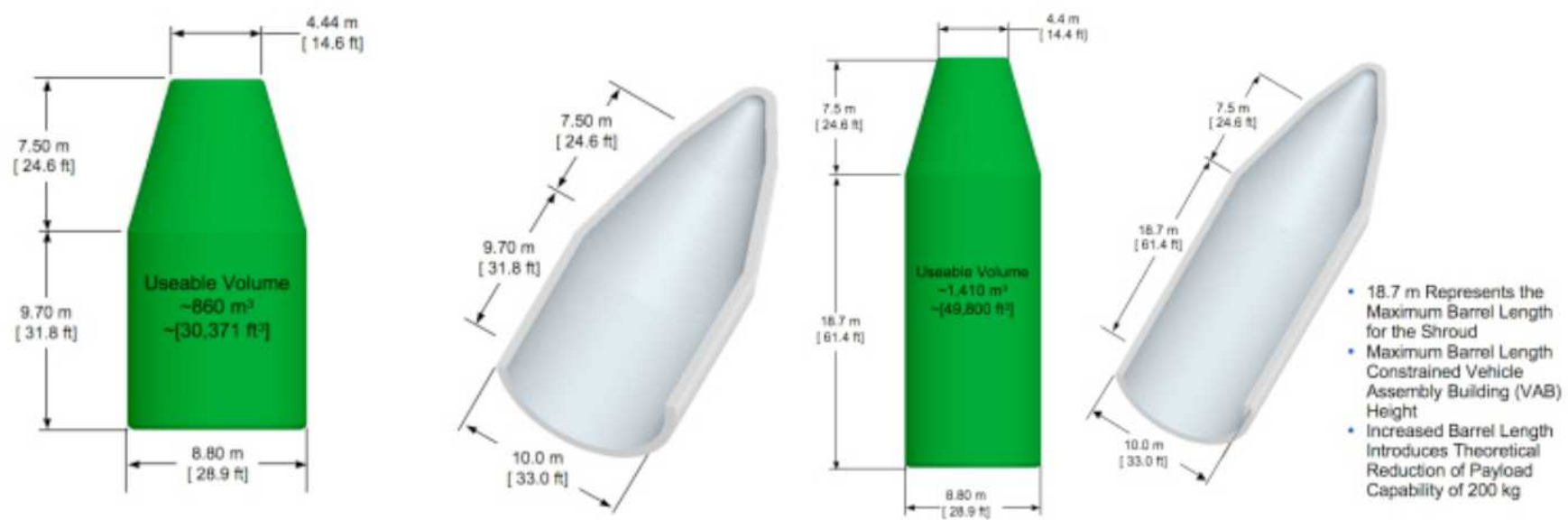

Figure 6 - Payload shroud volume for point-of-departure Ares V, left, and notional science payload shroud

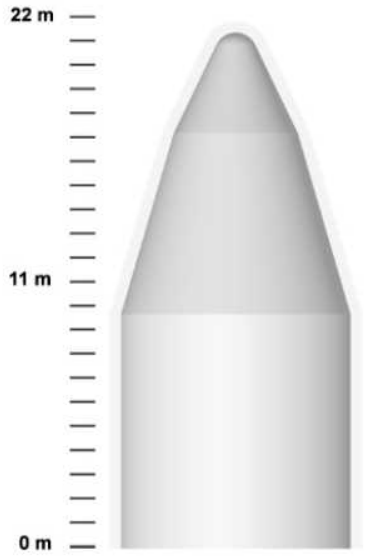

Ares V

$10 \times 9.7$

$\sim 561 \mathrm{~m}^{2}$

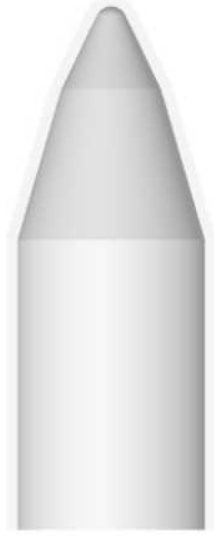

Ares V

$8.4 \times 12$

$\sim 493 \mathrm{~m}^{2}$
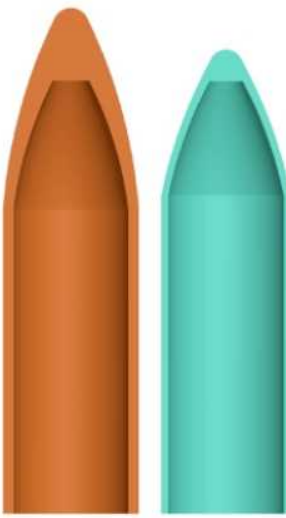

Atlas V

$5.4 \times 12.4$

$\sim 311 \mathrm{~m}^{2}$

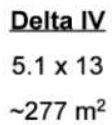

$\sim 277 \mathrm{~m}^{2}$

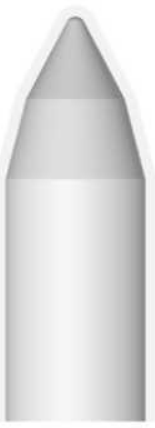

Skylab

$6.5 \times 10$

$\sim 305 \mathrm{~m}^{2}$
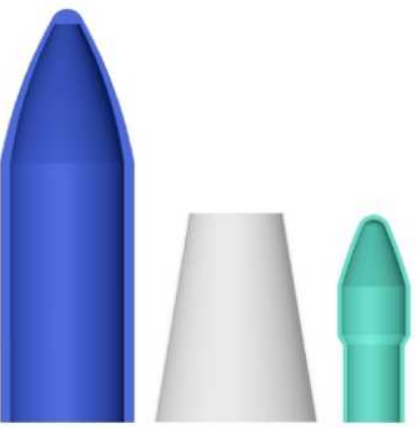

Ariane

Apollo SLA

$5.4 \times 10.6 \quad 6.6 / 5.6 \quad 3 \times 4.2$

$\sim 254 \mathrm{~m}^{2} \quad \sim 142 \mathrm{~m}^{2} \quad \sim 63 \mathrm{~m}^{2}$

Figure 7 - Ares V shroud options as measured against previous and current payload shrouds

Analysis of the reference vehicle's mass and volume in relation to mission design give a better idea of its capabilities. Figure 8 below shows the 51.0.39 vehicle's payload mass (metric tons) to Low Earth Orbit as a function of Orbit Altitude and Inclination Angle. The higher the orbit, or greater the inclination angle, the less mass can be launched. This analysis was based on the pre-LCCR 51.00 .39 configuration. Current configuration capability is expected to be approximately $40,000 \mathrm{~kg}$ more or approximately $180,000 \mathrm{~kg}$ to LEO. 
Ares V Payload vs. Altitude \& Inclination (LV 51.00.39)

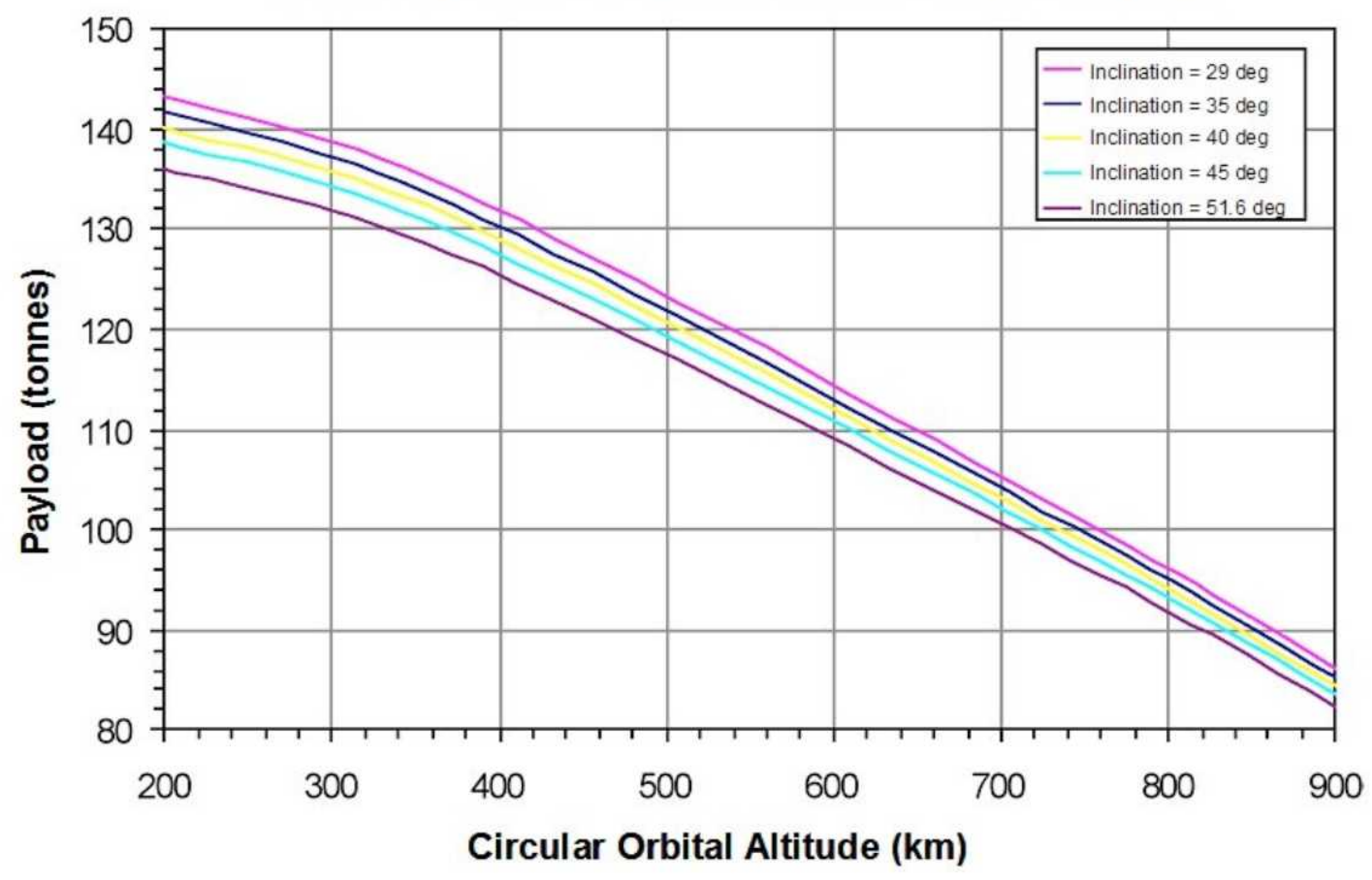

Figure 8 - Ares V payload mass vs. altitude and inclination.

Figure 9 shows that Ares V alone or with a Centaur Upper Stage can accelerate previously unachievable masses (metric tones) to extremely large C3 energy values, thus enabling and enhancing deep space planetary missions or missions outside of the ecliptic plane. Again, this data is for the earlier 51.00.39configuration.

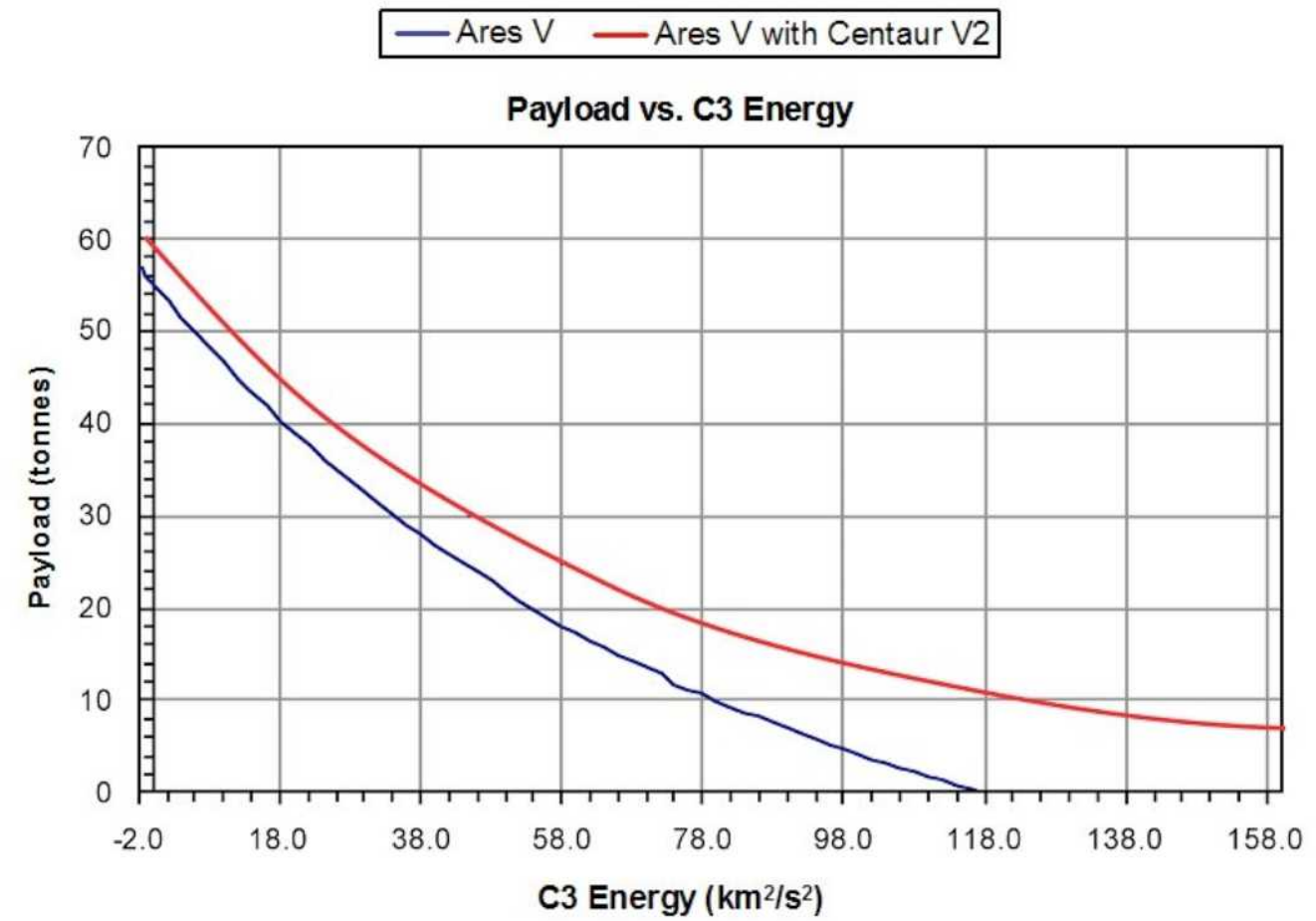

Figure 9 - Ares V payload mass vs. C3 Energy. 
The Ares team has engaged potential users at the early conceptual stage when an exchange of information can have the greatest impact at the least technical and fiscal cost. While the human lunar mission is the primary purpose for the Ares $\mathrm{V}$, outreach efforts to the payload community have attempted to quantify unique requirements that vehicle designers can incorporate or at least not preclude in exploring design solutions for the human lunar mission.

NASA's Ames Research Center hosted two weekend workshops devoted to Ares V's potential for astronomy and planetary science. These meetings brought together payload and vehicle designers to examine the Ares V design and payloads that might take advantage of its capabilities. The reports from both workshops concluded Ares $\mathrm{V}$ would benefit both fields of exploration.

"The workshop clearly showed that the Ares V has considerable potential to do breakthrough astronomy," the astronomy workshop final report said. "It is also likely that it could advance the Earth science and planetary science goals of NASA.

Likewise, the planetary workshop final report noted that heavy-lift changes the paradigm of the possible for payloads because its C3 versus payload is far greater than that of any current vehicle. The massive payload shroud permits the launch of large, multi-element systems, larger power supplies, and more low-tech mass for shielding or propellants. "This translates into an earlier return on science, a reduction in mission times, and greater flexibility for extended science missions," the report states. "It is particularly enabling for sample return, which takes advantage of all of the Ares V capabilities. We encourage the science community to think big, because an Ares V expands the envelope of what can be done in planetary science.

The National Research Council (NRC) took note of Ares V in its report, Launching Science: Science Opportunities Provided by NASA's Constellation System. The Ares V provides significantly greater launch mass and C3 performance over present U.S. expendable launchers. For LEO missions, Ares V provides four to seven times the mass to orbit of the other systems. Similarly, the Ares V, with or without the Centaur upper stage, offers dramatically greater performance for interplanetary missions than the Delta IV.

The report cautioned that astronomy and astrophysics payloads will require cleanliness, vibration, and noise levels at least as low as the space shuttle. NASA's heavy-lift team is investigating designs to meet those levels. Planetary missions will need a way to remove waste heat from radioisotope power sources inside the payload shroud, as well as access to the payload through the shroud. Again, the design team is investigating how to incorporate those requirements.

Although history indicates bigger payloads cost more than smaller payloads and that payload mass usually expands to fill the available vehicle capability, Ares V represents a potential departure from that paradigm. NASA's Advanced Missions Cost Model shown in Figure 10 indicates that design complexity is also a significant cost driver. The model plots estimated spacecraft costs as a function of payload mass for three classes of complexity for solar system exploration missions. 


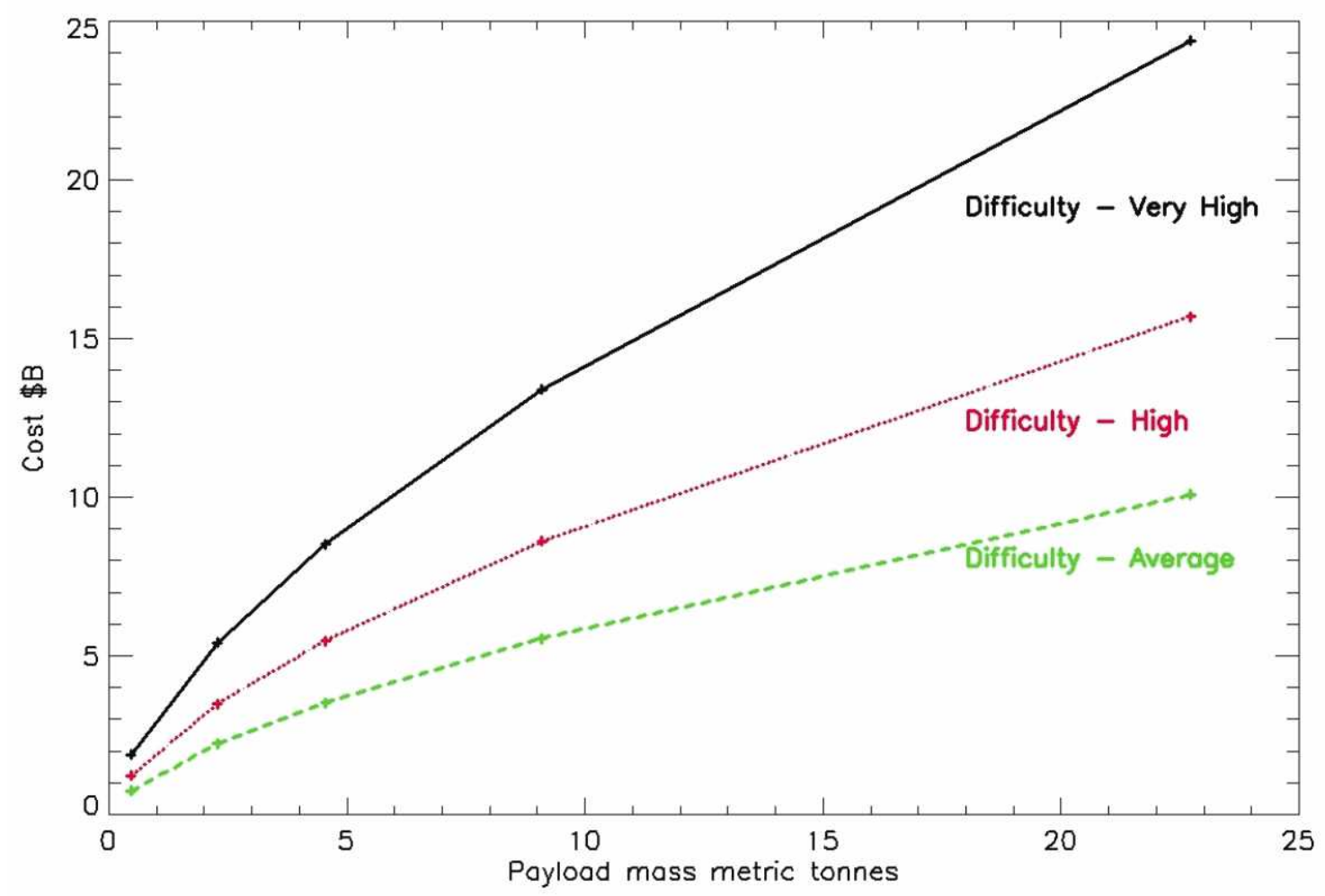

Figure 10 - NASA's Advanced Missions Cost Model

Ares V's "excess" mass and volume could be used to reduce technical complexity, redesign cycles, and cost. The NRC report concluded that program managers will then be faced with a different problem. "The capabilities of the Ares $\mathrm{V}$ will enable even larger, more complex, and more capable systems than these-systems that can dramatically increase scientific return. With the advent of the Ares V, the challenge for program managers will be to temper the appetites of scientists who will clearly recognize the dramatic scientific benefits enabled by the launch system. There will need to be an enforced paradigm shift where cost, rather than launch system capability, is the design limiter.

Heavy-lift of the reference vehicle's magnitude allows the payload community to go either direction in the costversus-capability conflict. Figure 11 below shows the Hubble Space Telescope primary mirror. Hubble, launched in 1990, was limited to the size of the Space Shuttle cargo bay. To its right is the James Webb Space Telescope, which features a complex folding aperture that will be launched by the Arianne 5. Next is the proposed 8-Meter Monolithic Space Telescope that would use simple, heavy, ground-based telescope technology to take full advantage of Ares V volume and mass capability. Finally, there is the Advanced Technology large-Aperture Space Telescope, a complex segmented telescope designed to push Ares V's volume capability to the limit. The difference between the 8-meter monolithic and the 16-meter ATLAST is a $\$ 3$ billion to $\$ 10$ billion comparison.

The NRC report recommended that NASA should conduct a comprehensive systems-engineering-based analysis to assess the possibility that the relaxation of weight and volume constraints enabled by Ares $\mathrm{V}$ for some space science missions might make feasible a significantly different approach to science mission design, development, assembly, integration, and testing, resulting in a relative decrease in the cost of space science missions. 


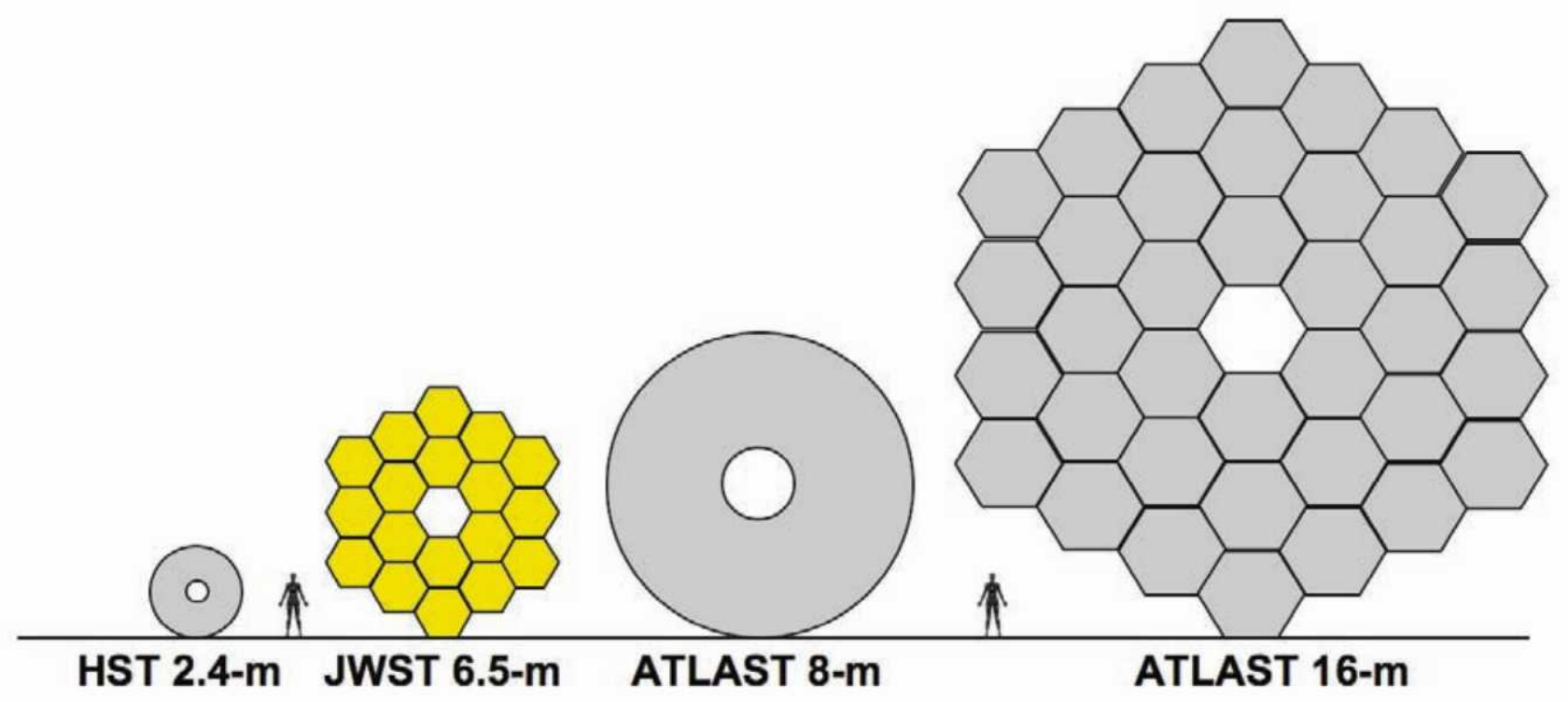

Figure 3 - The representative growth in space telescope apertures using Ares V

Most recently the Review of U.S. Human Space Flight Plans Committee, also known as the "Augustine Committee," considered heavy-lift important enough to include it as one of the five "key questions" for inquiry, and the need for heavy-lift vehicle was one of the panel's major findings in its summary report, released as this paper was in preparation.

"No one knows the mass or dimensions of the largest piece that will be required for future exploration missions, but it will likely be significantly larger than 25 metric tons $(\mathrm{mT})$ in launch mass to low-Earth orbit, the capability of current launchers," the panel concluded. "As the size of the launcher increases, fewer launches and less operational complexity to assemble and/or refuel those results, and the net availability of launch capability increases. Combined with considerations of launch availability and on-orbit operations, the Committee finds that exploration will benefit from the availability of a heavy-lift vehicle. In addition, heavy-lift would enable the launching of large scientific observatories and more capable deep-space missions. It may also provide benefit in national security applications."

\section{Conclusion}

NASA's heavy-lift cargo vehicle remains in a preliminary concept stage pending national policy decisions on the future of the Constellation Program. The current point-of-departure configuration has been shaped by a desire for employing proven hardware, commonality with the Ares I and formal design reference missions that include both lunar and Mars exploration missions. This design meets the official payload requirement, but work continues to refine the current configuration and understand the impact of a wide range of trades, including greater use of space shuttle components, new development components, and possible new space transportation architectures. Work is also ongoing in the wider systems aspects of the design, such as manufacturing and launch facilities. Its unprecedented size presents challenges to vehicle and facility designers. NASA's heavy-lift team is prepared to provide a heavy-lift vehicle tailored to any future national direction that requires the capability. While NASA's current focus is on beyond-LEO exploration, starting with the Moon and evolving to Mars, heavy-lift represents a national asset for science, national security, and commerce. In that light, the Ares Projects are also reaching out to the academic and government community for payload and design inputs on science and military missions that may benefit from such a heavy-lift capability. The kind of heavy-lift capability currently represented by Ares V can launch more capable science spacecraft farther, shorten trip times, and increase scientific return on missions that otherwise might be launched on today's launchers. It could also enable certain kinds of missions, such as sample return, that would be impossible on today's fleet. While payload and mission designers can use traditional technical complexity to fully exploit a significant new heavy-lift capability, they can also use that capability in innovative ways to better manage technical and program risks. 


\section{Heavy Lift for a New Paradigm in Space Operations}

K. Bruce Morris Exploration and Space Systems Manager NASA Marshall Space Flight Center 


\section{Approach to Engage Beyond Exploration}

- Early in the process, Senior NASA Management recognized unique opportunity provided by Ares Heavy Lift capabilities:

- Coming on-line early 2020

- Heavy Lift capability

- 5x Current Payload Volume

- Production sized for one additional flight alternating years

- Non-Recurring costs budgeted for as part of primary mission

- Proactively embrace potential users

- History of Shuttle shows less science utilization in the initial 10 years

- DoD, Scientific Research, Human Spaceflight beyond LEO all will be possible meaning the stakeholder base is quite broad

- Facilitate conversation and develop preliminary needs with potential users

- Focus energies on building value proposition 


\section{Current Ares V Reference Configuration}

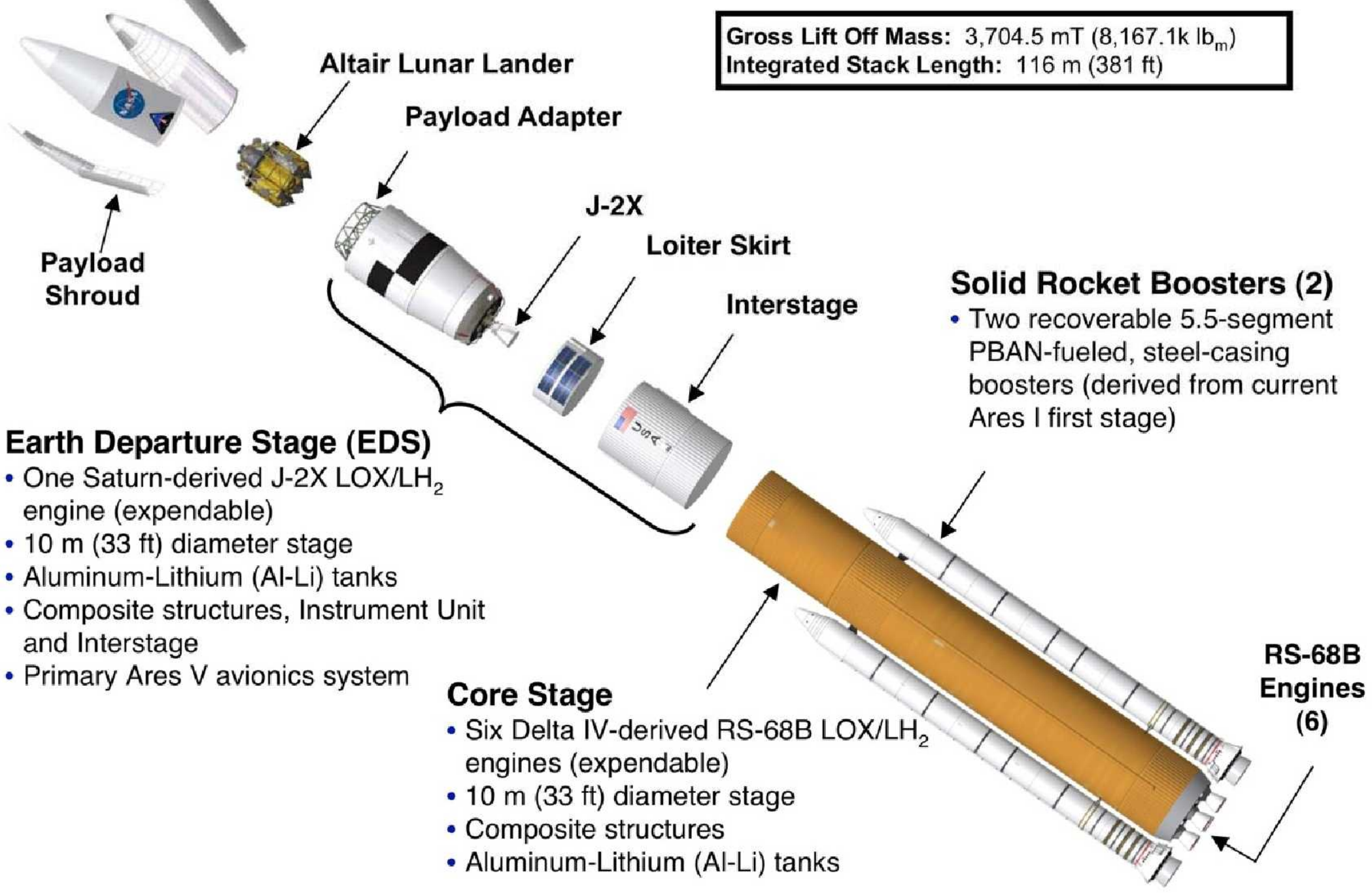




\section{Ares V Evolution from ESAS to LCCR}
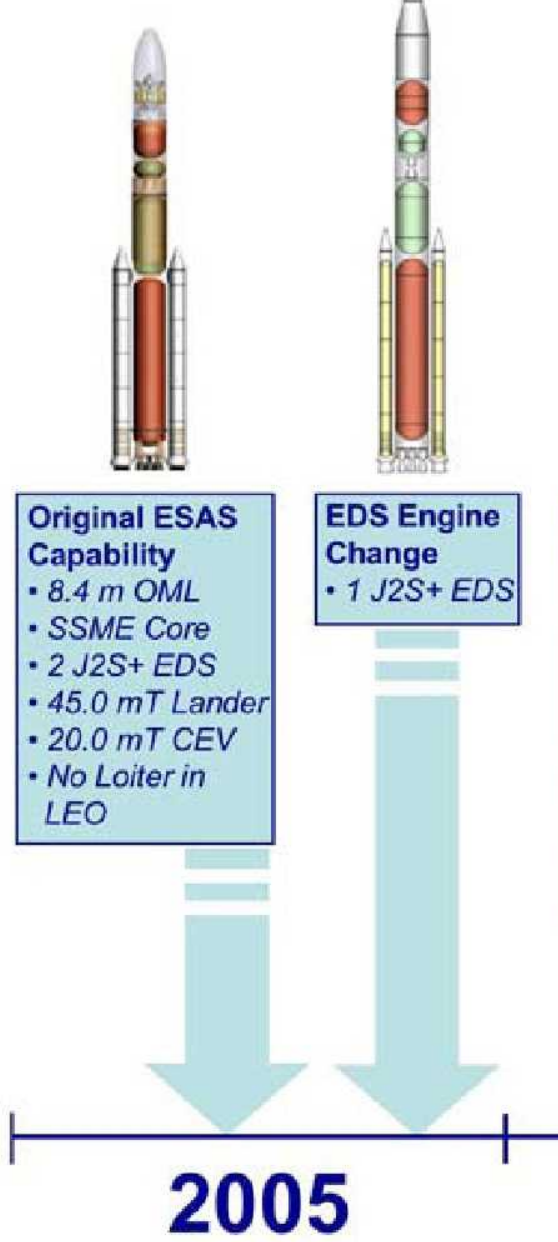

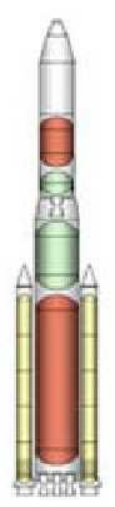

\section{Change to RS-68B}

Core Engines

- Core dia: $8.4 m$ to

$10 \mathrm{~m}$

- Fvac: $490 k$ to $750 k$

- Isp: 452.1 to 414.7

sec

- Booster: HTPB to

$P B A N$ propellant

(Ares I 53-06 thrust

trace)

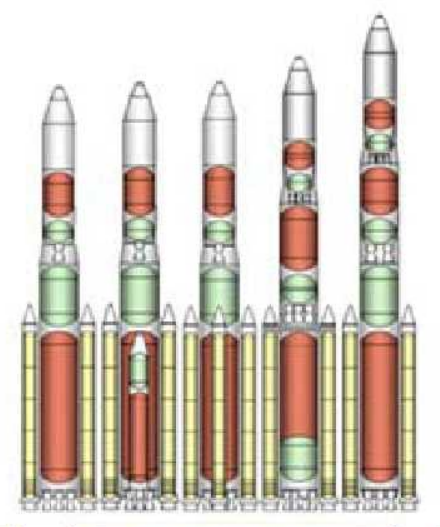

IDAC 3 Trade Space

- SRM Propellant

- Stage Materials

- Extra Strapons

- Engine Type

- 10+m dia. Core

- Number of Stages

- Shrouad Material

- Shroud Size

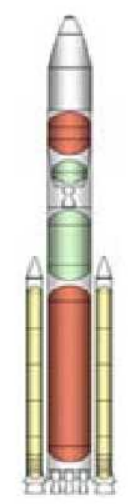

\section{Diameter} Change

- 10 m diameter

EDS and

Shroud

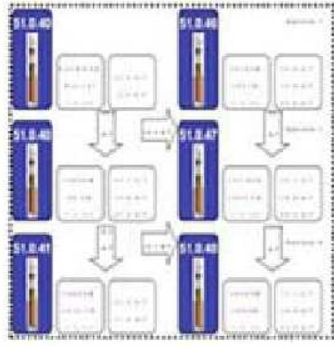

\section{LCCR Options}

- 5.5 Segment

- Inert Spacers

- HTPB SRB Prop

- Composite Case

SRB

- 6 Engine Core
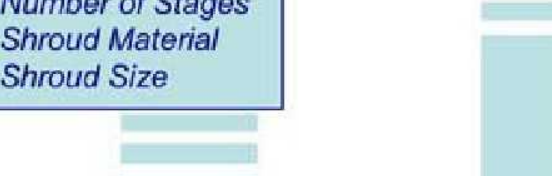

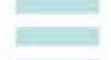

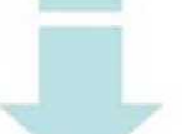

\section{Current POD}

- 6 Core Engines

- 5.5 Segment

PBAN

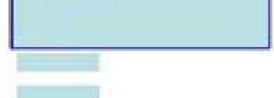




\section{Requirements for Lunar Crew, Cargo Missions}

LUNAR SORTIE MISSION

\begin{tabular}{|l|l|l|l|}
\hline CARD Requirement & Mass $(\mathrm{t})$ & Mass $\left(\mathrm{Ib}_{\mathrm{m}}\right)$ & Derived Performance Rqt. \\
\hline Orion [CA4139] & 20.2 & 44,500 & \\
\hline Crewed Lander [CA0836] & 45.0 & 99,208 & \\
\hline Total TLI [CA0848] & 66.9 & 147,575 & Derived TLI > 66.9 t \\
\hline & 45.0 & 99,208 & Derived ETO $>45.0 \mathrm{t}$ \\
\hline
\end{tabular}

- ETO Mission Destination: $130 \mathrm{nmi}, 2^{\circ}$

- Loiter Duration: 4 days (CARD TBD)

- TLI Maneuver Starting Conditions: $100 \mathrm{nmi}, 2^{\circ}$

- TLI $\Delta V=3175 \mathrm{~m} / \mathrm{s}+$ Gravity Loss

\begin{tabular}{|l|l|l|l|}
\hline \multicolumn{4}{|c|}{ LUNAR CARGO MISSION } \\
\hline CARD Requirement & Mass $(\mathrm{t})$ & Mass $\left(\mathrm{Ib}_{\mathrm{m}}\right)$ & Derived Performance Rqt. \\
\hline Cargo Lander [CA5231] & 53.6 & 118,168 & \\
\hline Total TLI [CA0847] & 54.6 & 120,372 & Derived TLI > 54.6 t \\
\hline Total ETO Goal [CA0847] & 54.6 & 120,372 & Derived ETO > 54.6 t \\
\hline
\end{tabular}

- ETO Mission Destination: Phasing Orbit

- Loiter Duration: None (no loiter capability on EDS)

- Note that Saturn V TLI payload capability was $48.6 \mathrm{t}$ (Apollo 17 - CM/SM/ LM/SLA) and

- Ares V Earth-to-TLI requirement exceeds Saturn V Capability by $31 \%$ 


\section{Architecture Flexibility Enables New Science Applications}

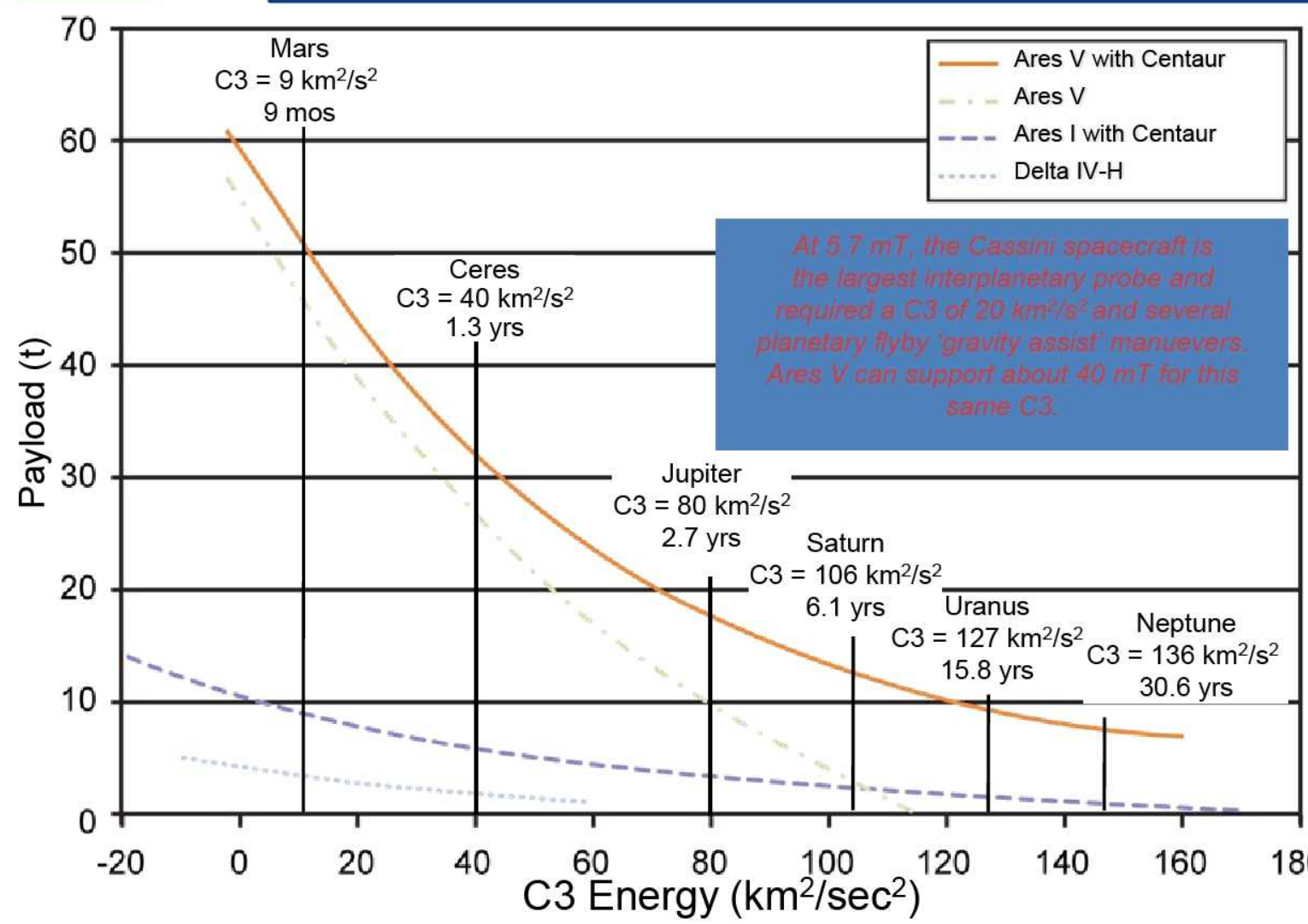

"It is very clear from the outset that the availability of the Ares $V$ changes the paradigm of what can be done in planetary science."

- Workshop on Ares V Solar System Science

"Exciting new science may be enabled by the increased capability of Ares $V$. The larger launch mass, large volume, and increased C3 capability are only now being recognized by the science community."

- National Academy of Science's "Science Opportunities by NASA's Constellation

Program"

\section{Large Payload Volume and Lift Capability}
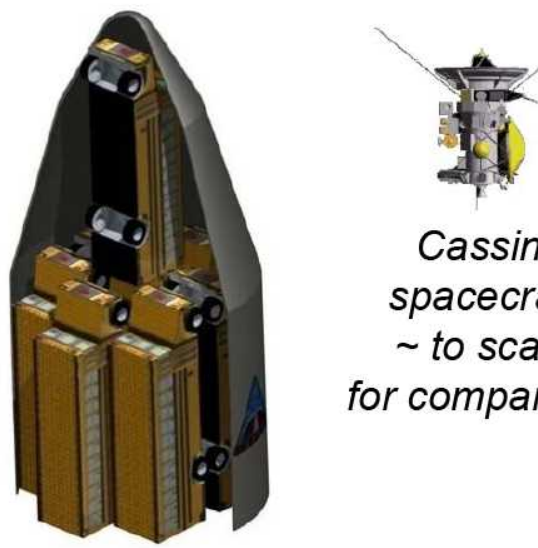

Cassini spacecraft

to scale for comparison

Ares $V$ will have the largest payload volume capability of any existing launch system

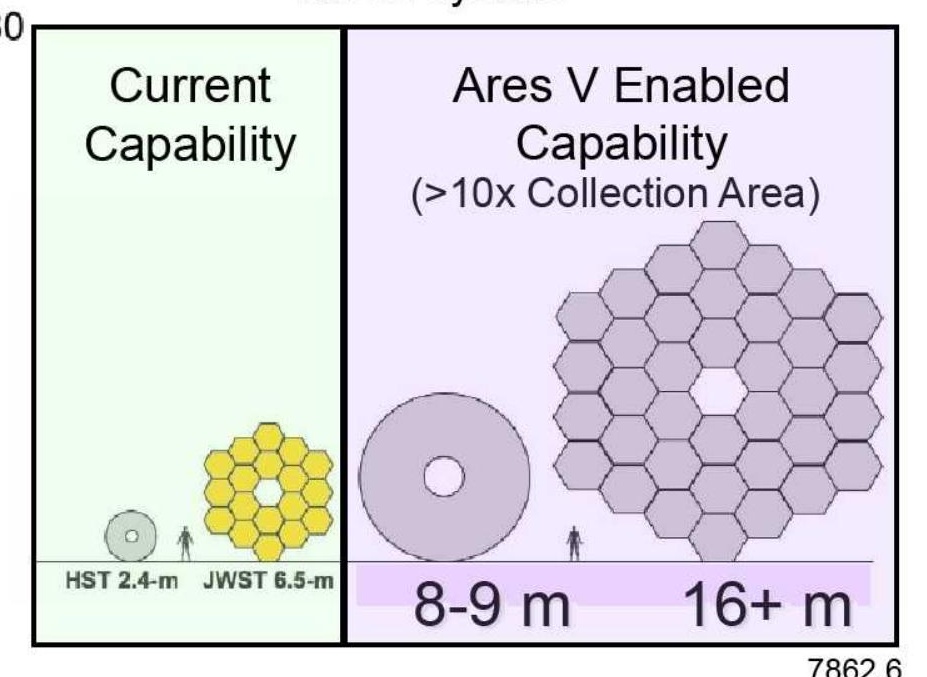




\section{Ares V Class Heavy Lift Science Workshops}

\section{- Two Workshops held at ARC ... Industry, Academia, Government}

- Astronomy Workshop (NASA/CP-2008-214588) ... from Executive Summary

- The workshop clearly showed that the Ares $\mathrm{V}$ has considerable potential to do breakthrough astronomy

- Large fairing and lift capabilities of the Ares $V$ open up new design concepts, e.g., large monolithic mirrors ... reduce complexity, cost, schedule

- Larger-aperture telescopes offer much higher sensitivity and spatial resolution than telescopes that can be launched with current launch vehicles

- This is particularly important for studies of the early Universe and for imaging exosolar planets

- Solar Science Workshop (NASA/CP-2008-214592) ... from Executive Summary

- Ares $V$ class heavy lift changes the paradigm of what can be done

- Approximately five times the payload mass to Mars compared with current Launch Vehicles

- Capable of much larger C3s (hyperbolic excess speed over escape, squared) ... opens up direct missions to the outer planets

- Large payload capacity of the Ares V permits the addition of "cheap", but useful mass. Ideas included extra fuel, shielding, and redundancy.

- Sample return missions benefit from all aspects of the Ares $V$ performance, including the potential enabling of

- Sample return from Jupiter's moon Europa

- Sample capture from the plumes on Enceladus

- Multiple rovers on the surface of Venus 


\section{Planetary Science Workshop}

- The Increased Launch Performance Benefits Planetary Science

- Enabling much larger payloads for a given C3, or

- For a given payload, much higher C3s ... reduces trip times especially to the outer planets or to Mercury

- The Greater Launch Mass and Volume of the Ares V Benefits Planetary Science in a Number of Ways:

- The launch of large, complex systems such as multiple probes, orbiters, landers, etc.

- Greater science instrument mass and mass fraction

- Larger electric power supplies for instruments and telecom transmitters

- Greater post-launch Delta-V for expanded access and access to multiple destinations

- Greater mass for shielding against radiation exposure or other environmental hazards

- Greater mass/volume for lower-complexity engineering solutions, such as propulsive orbital insertion and allow redundant systems

- Large Interior Diameter of the Fairing

- Enables using large apertures for optical instruments or for aero shells

- Simplifies packaging of large, complex systems

- Simplifies the launch configuration of multi-element missions. 


\section{Astronomy Workshop}

- Search for Life - In the Search for Life in the Galaxy, need to obtain the spectra of an Earth-Twin atmosphere with sufficient signal-to-noise and resolution to determine if biological processes are present

- 8-m is the minimum aperture necessary to make truly revolutionary advances in astrophysics.

- Study of Galaxy and Star Formation - breakthroughs require the study of stellar populations in many different galaxy environments such as dwarf galaxies and giant spiral and elliptical galaxies

- 8-m class telescope can, with difficulty, determine the subtle transverse motions of stars enabling the measurement of density profiles.

- 16-m can do this with ease.

- Study of Dark Matter - Explore the far IR (20 to $300 \mu \mathrm{m})$ universe with higher sensitivity and spatial resolution than ever achieved

- 8-m can reach 140 galaxies including 12 giant spirals and 1 giant elliptical.

- 16-m extends reach to the Coma Sculptor Cloud, netting a total of 370 galaxies including 45 giant spirals and 6 ellipticals

- Increased Volume of Ares V Provides Untapped Flexibility 


\section{Summary}

- Ares V-class heavy lift changes the paradigm of what can be done

- "Large mass and volume capabilities of the Ares Heavy Lift can be used to trade off complexity and thereby reduce technology development and integration costs."

- "Large fairing makes feasible launching large monolithic mirrors that may be less costly to build and less risky to deploy."

- "For the payload developer the challenge will be to use the margin to lower risk and cost, not design to it ..."

- "Large payload capacity of the Ares V permits the addition of "cheap", but useful mass. Ideas included extra fuel, shielding"

- Redundant systems are now practical for national assets on other applications

- Sample return missions benefit from all aspects of the Ares Heavy Lift performance

- For Earth science and Astrophysics the Ares Heavy Lift would be most useful for placing large observatories either in geostationary orbit (GEO) or at the Sun-Earth Lagrange points (L1 and L2)

- Heliophysics missions that explore the interaction of the outer heliosphere and local interstellar medium benefit from the large C3 capability of the Ares Heavy Lift 


\section{QUESTIONS?}




\section{Planetary Science - Sample Return Missions}

- Sample Return from Europa and Enceladus Using the Ares V

- Provide shielding from the harsh radiation environment and mass for Delta-V that is needed either for landing or sample capture

- Multi-Spacecraft Mission to Saturn Enabled by Ares V

- Atmospheric Probes, Ring Observer, and "Beyond Cassini" Orbiters

- Multiple probes help ensure a representative sampling of the atmosphere. Total flight system mass is estimated to be $15,000 \mathrm{~kg}$.
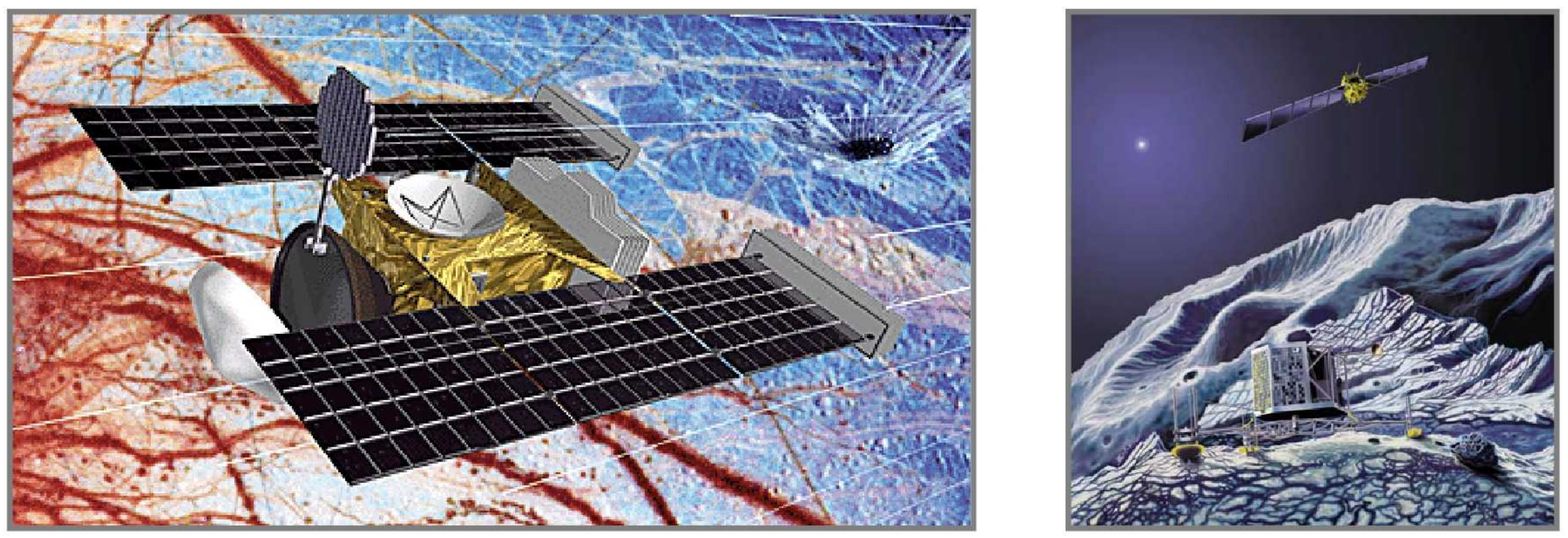


\section{Planetary Science - Sample Return Missions}

- Constellation-Enabled Mars Mission Exhibiting New Technology (CEMMENT) Mars Sample Return Mission

- Looked at what Mars sample return missions can be done

- Other human-precursor demonstrations

- Constellation flight elements including the Ares $\mathrm{V}$

- 3 x $500 \mathrm{gm}$ separate samples were returned, from two separate Martian locations with an excursion mobility of $>1$ $\mathrm{km}$, and at one location adding subsurface sampling to a 10-m depth

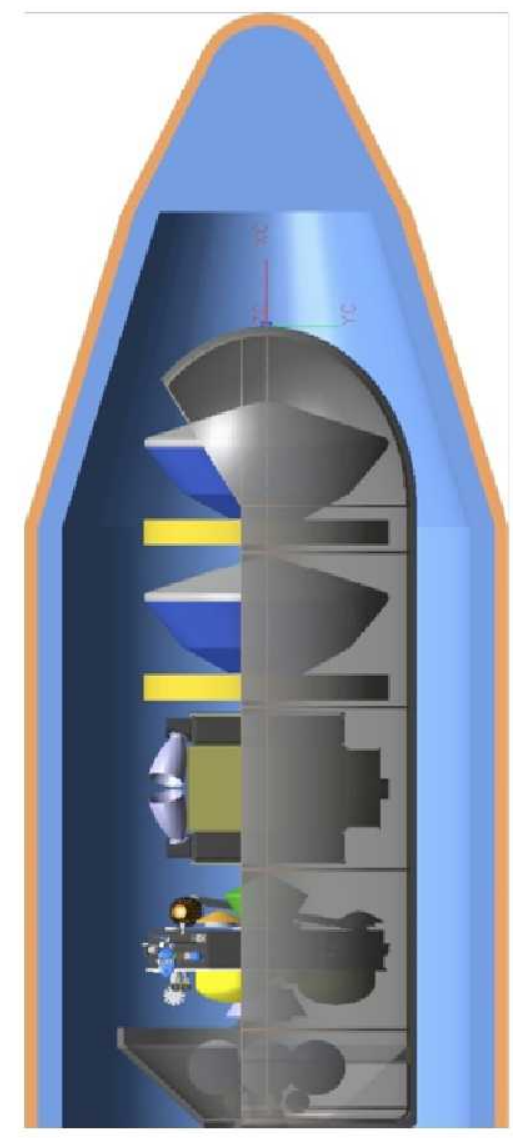




\section{Planetary Science - Outer Solar System}

- Large Planetary Probes Enabled by Ares V: Exploration of the Kuiper Belt

- Allows a larger volume for much larger instruments, for example, larger apertures and more capable detectors with larger wavelength range and sensitivity, and more robust mass spectrometers

- Enables greater power (>few kW), higher data |volume and rate, mass for surface probes, and autonomy for other operational innovations such as laser communications

- Ares Heavy Lift would enable larger science payloads to Pluto and other KBOs

\section{- Alternative Approaches to Outer Solar} System Exploration

- Impactor creates an artificial plume

- Europa Ice Clipper intercepts

- Heavy lift allows for radiation-hardened electronics or shielding for a long duration orbiter.

- Similar mission could be attempted for Enceladus ... natural plumes

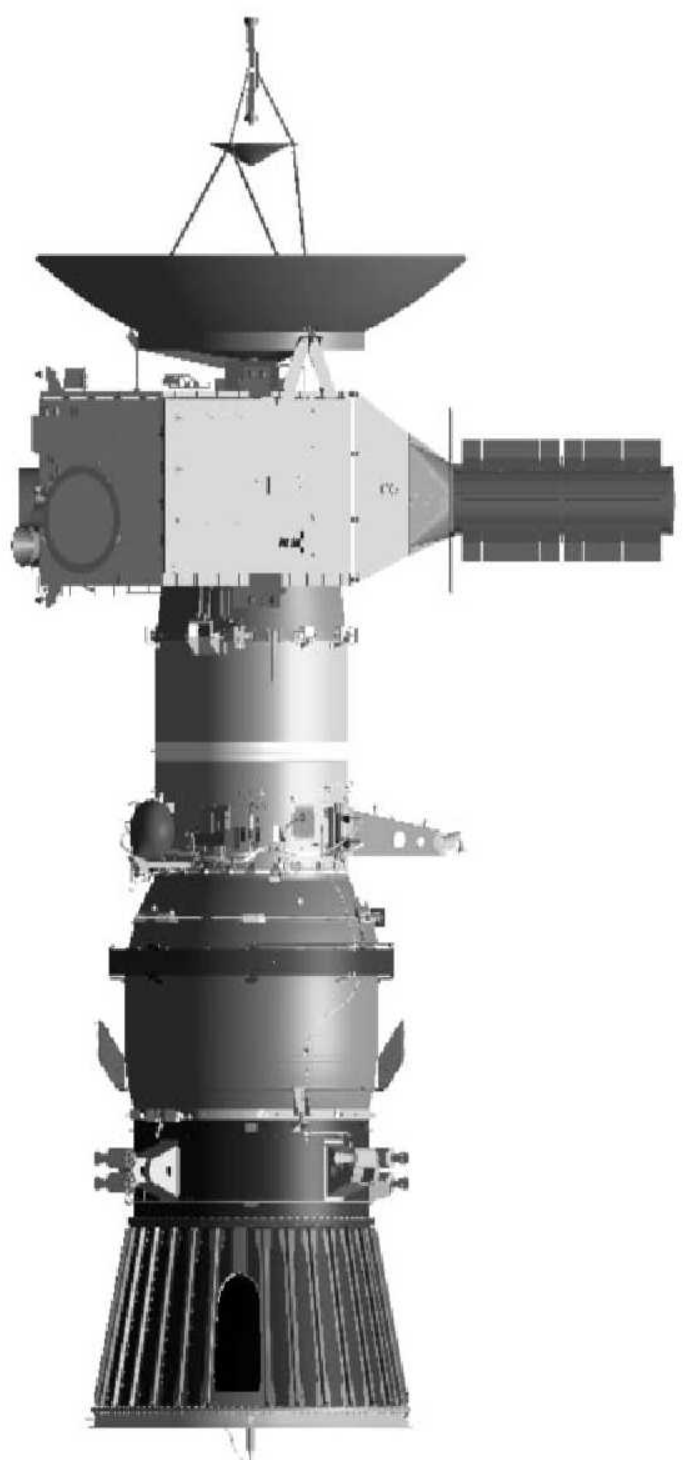




\section{Planetary Science - Missions to NEOs}

- Constellation Enabled Missions to NEOs

- Dual launch for crew

- Depending on the target, the outbound segment is $\sim 20-75$ days, with a 7-14 day visit at the NEO, and a $\sim 45+$ day return trip to Earth

- Best targets for the mission are NEOs that have approaches to Earth during the time frame of 2020-2035

- Current database of existing NEOs - nine potential targets within the available Delta- $V$ and mission length capabilities of the proposed Constellation systems

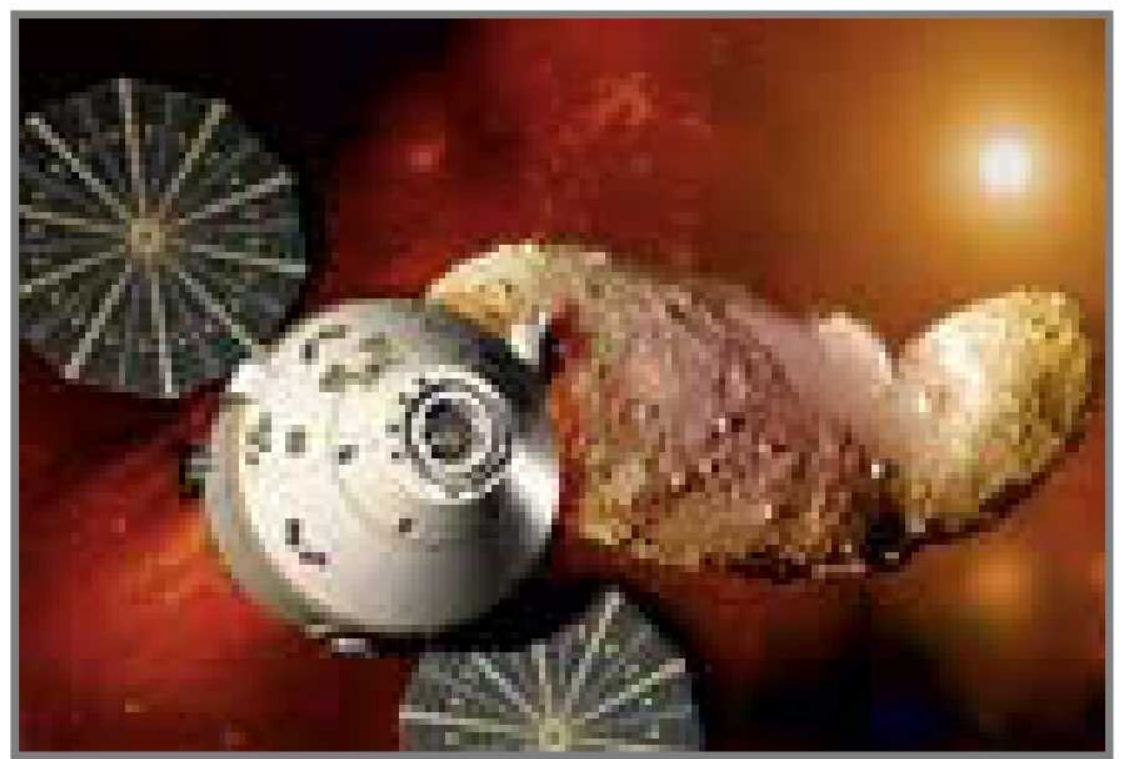




\section{Mission Concepts - Astronomy}

ATLAST $8 \mathrm{~m} / 16 \mathrm{~m}$

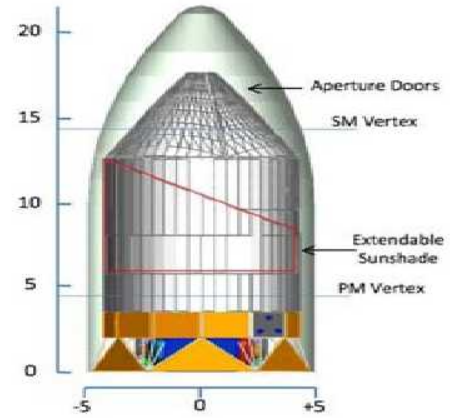

Figure 2.8: ATLAST-8m is shown in its launch configuration in an Ares- $V$ ogival fairing. The scarfed end of the sunshade is deployed once on-orbit. Length scales are in meters.
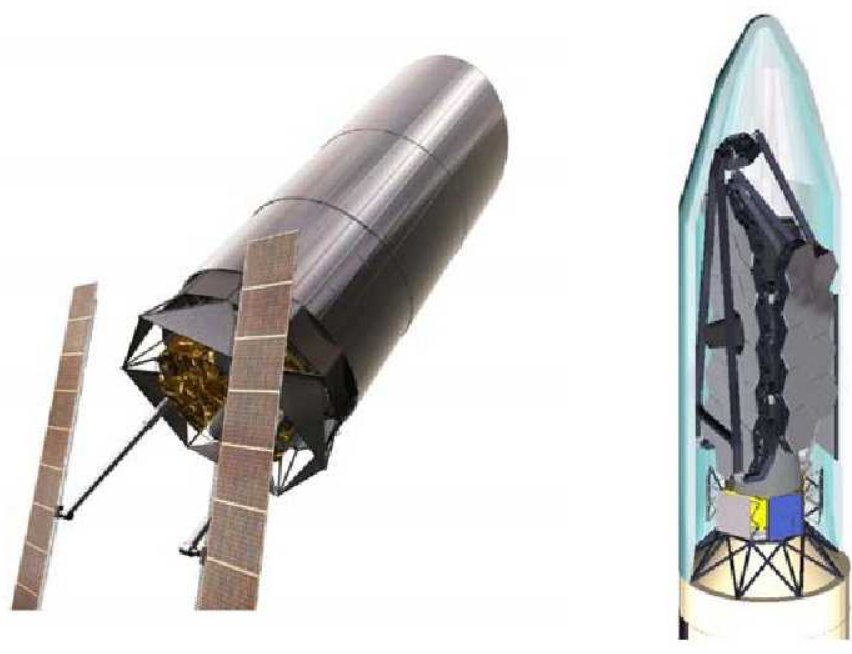

\section{SAFIR}

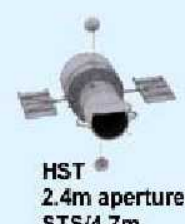

$2.4 \mathrm{~m}$ aperture
STS $4.7 \mathrm{~m}$

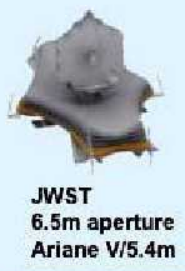

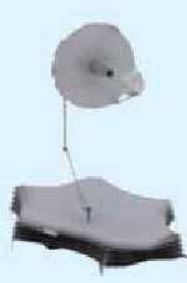

SAFIR Monolith

$8 \mathrm{~m}$ aperture Ares V/10m
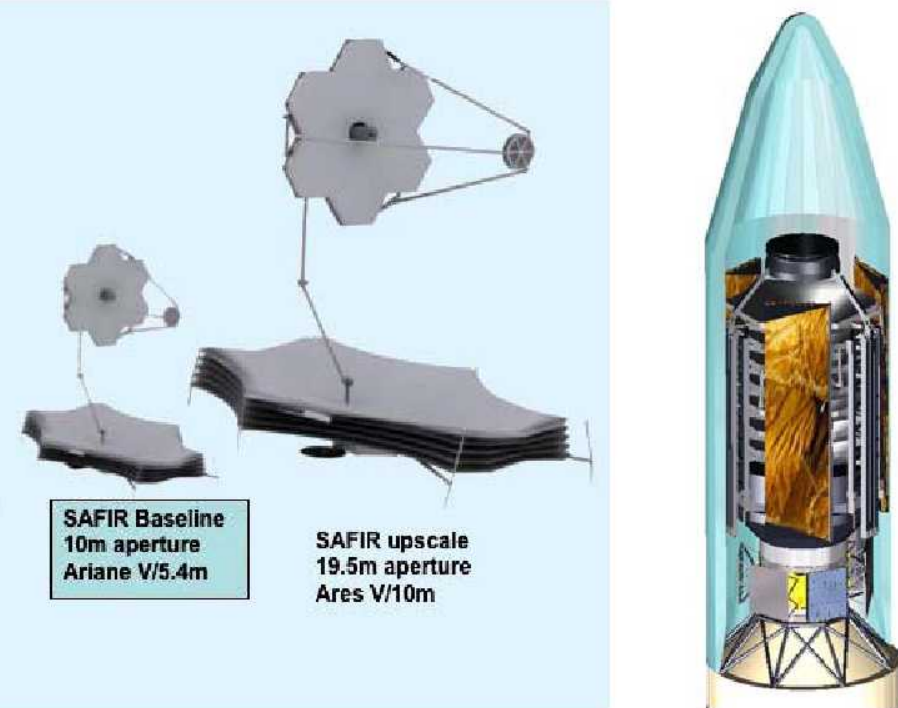


\section{Mission Concepts - Astronomy}

\section{$\checkmark$ Gen -X}

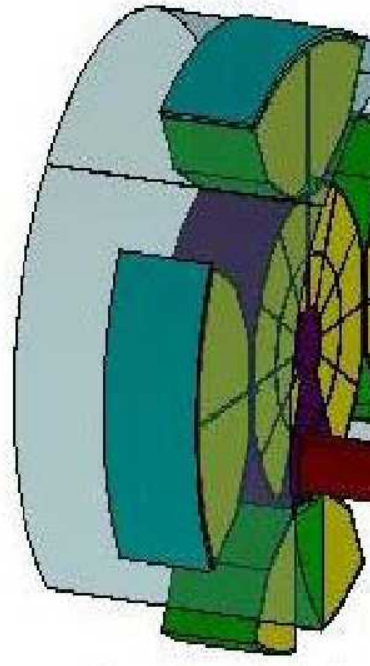

Grazing Incidence

$\mathrm{X}$-ray Optics
Telescope

Sunshade
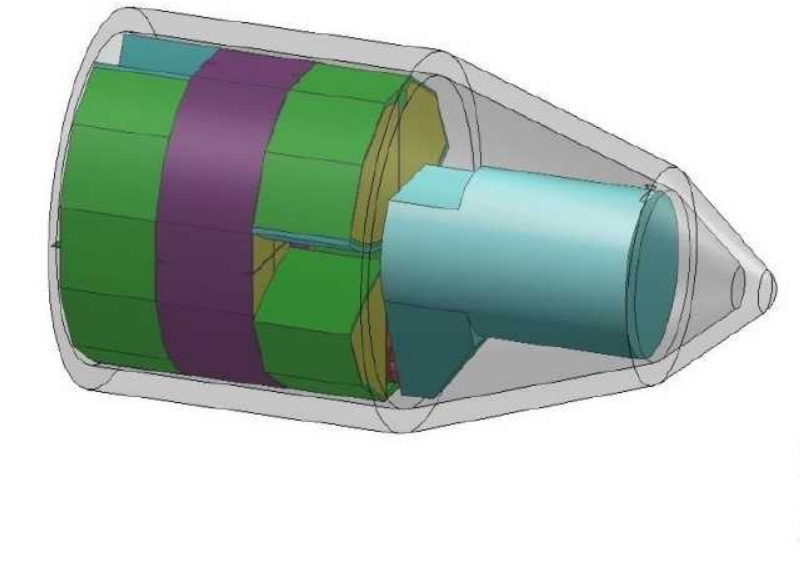

Grating

Array

X-ray

Baffle

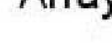

10

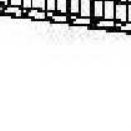

Extendible $60 \mathrm{~m}$

Optical Bench
Spacecraft Bus and Science Instruments 


\section{Mission Concepts - Astronomy}

- Interstellar Probe Mission

- Designed to study the nature of the nearby interstellar medium, the structure of the heliosphere, and how the Sun and galaxy affects the heliosphere's dynamics

- To reach the heliopause in a reasonable length of time requires the large C3 capability of the Ares $V$ and its ability to launch an upper stage

- Estimated that an Ares V would speed up arrival to $1000 \mathrm{AU}$ by about 31 years over existing launch vehicles

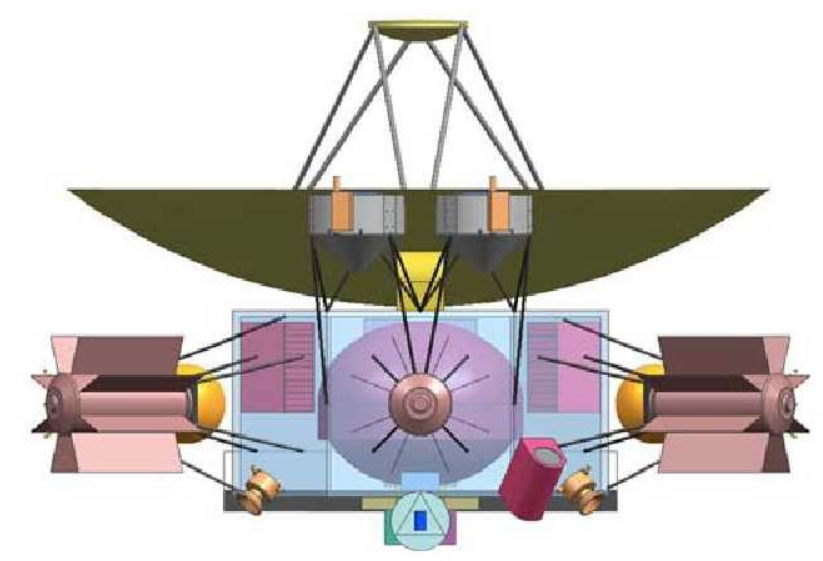




\section{Mission Concepts - Science and Heliophysics}

- Earth Observation Targets: 2020 and Beyond

- Potentially enable new capability in large GEO platforms

- Large apertures (>10 m) microwave sounders

- Spatial resolutions $(<4 \mathrm{~km})$ measurements of temperature and moisture soundings, rain measurements, and severe weather monitoring and prediction

- Synthetic aperture radars for surface wind measurements

- Enable Large Aperture Telescopes at the Sun-Earth Lagrange Points (L1 and L2)

- Synoptic view, high time resolution, sunrise to sunset coverage, and long integration times

- L2 Earth Atmosphere Solar-Occulation Imager - designed to measure greenhouse gases using a 10-m infrared telescope 


\section{Potential Heavy Lift Payloads and Drivers}

\begin{tabular}{|c|c|c|c|c|c|c|c|}
\hline & SAFIR & ATLAST & SI & Gen $X$ & SPECS & $\begin{array}{r}\text { Dark } \\
\text { Ages } \\
\end{array}$ & Starshade \\
\hline Volume (Driver $\mathrm{Y} / \mathrm{N}$ ) & Yes & Yes & Yes & Yes & Yes & No & Yes \\
\hline Mass (Driver $\mathbf{Y} / \mathrm{N}$ ) & No & No & No & No & No & Yes & No \\
\hline Shroud Length & No & Yes & Yes & No & No & No & Yes \\
\hline Shroud Diameter & No & $\mathrm{No}^{1}$ & No & Yes $^{2}$ & Yes & No & No \\
\hline $\begin{array}{l}\text { Acoustic (Driver } \mathrm{Y} / \mathrm{N} \text { ) } \\
\text { No = Current Shuttle Environment }\end{array}$ & No & No & No & No & No & No & No \\
\hline $\begin{array}{l}\text { Cleanliness (Driver } \mathrm{Y} / \mathrm{N} \text { ) } \\
\text { No = Current Shuttle Environment }\end{array}$ & No & No & No & Yes $^{3}$ & No & No & No \\
\hline $\begin{array}{l}\text { Power/Data (Driver Y/N) } \\
\text { No = Current Shuttle Environment }\end{array}$ & No & No & No & No & No & No & No \\
\hline Other Sensitivities & No & No & No & UNK & No & No & No \\
\hline $\begin{array}{l}\text { Enabling (ENB): Enhancing } \\
\text { (ENH) }{ }^{4}\end{array}$ & ENH & ENB & ENH & ENB & ENH & ENB & ENH \\
\hline
\end{tabular}

Notes:

UNK = Unknown at this time

${ }^{1}$ Assumes 16-m segmented telescope will be folded for its launch configuration

2 Non-folded 12-m telescope

${ }^{3} \mathrm{X}$-ray and near-UV optics may need better cleanliness

4 "Enabling" means enabling in a single launch vehicle, perhaps with much lower deployment risk. "Enhancing" means that the baseline missions can be done in a smaller launch vehicle, but Ares $V$ offers straightforward opportunities for more ambitious versions of the mission. 


\section{DOD Contacts Made}

\section{Secretary of Defense}

\section{Deputy Secretary of Defense}

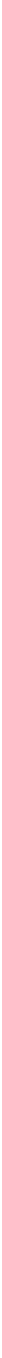




\section{Ares Heavy Lift /Volume Compared to Current Large Earth Orbital Satellites}

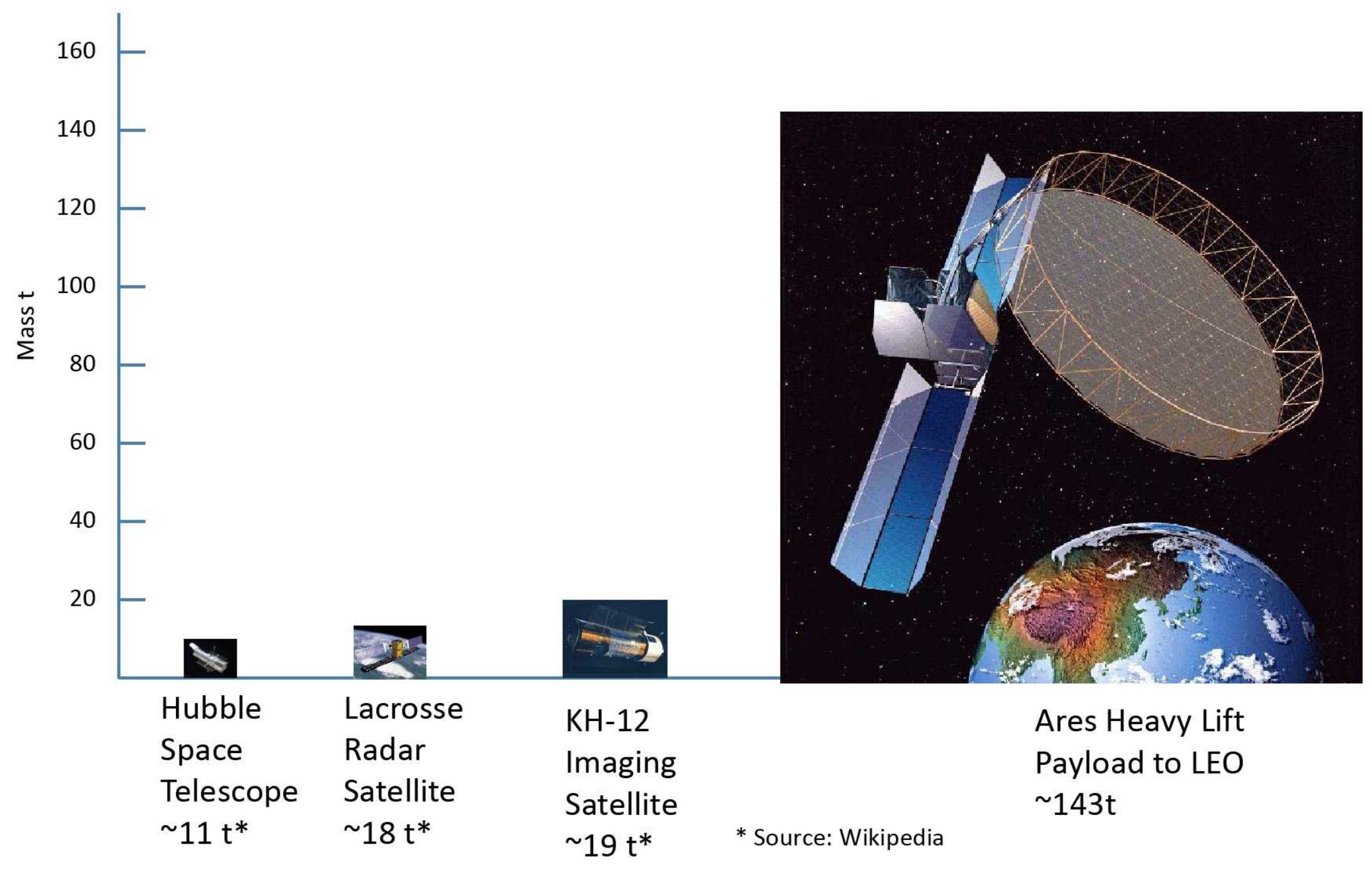




\section{NRC Study}

- In November 2007 NASA asked the National Research Council (NRC) to evaluate the potential for new science opportunities enabled by the Constellation system of rockets and spacecraft

- The Committee on Science Opportunities Enabled by NASA's Constellation System was formed to address this task

- Report was released based upon the Committee's evaluation of 11 pre-existing "vision mission" studies that were conducted for NASA from 2005 to 2006.

- Ares $\mathbf{V}$ team supported several meetings in Washington, Pasadena and Boulder 


\section{NRC Quotes and Items of Interest}

- "The unprecedented mass and volume capabilities of NASA's planned Ares $V$ cargo launch vehicle enable entire new mission concepts."

"....the Ares V would eliminate the need for multiple launches, complex packaging, and on-orbit assembly."

"The advent of the Ares V boosters promises to enable very large, very heavy science payloads to be delivered to orbits of interest. The Ares $V$ lift capability is expected to be five times larger than that of the current largest U.S. booster, the Delta IV Heavy. Similarly, the very large payload shroud of the Ares $V$ will be capable of housing payload volumes some three times larger than are currently feasible with a Delta IV." 


\section{NRC Quotes and Items of Interest}

- "The various mission proposals discussed in this report have identified multiple ways to take advantage of the increased lift capability and payload volume afforded by the Ares $V$. Those benefits can be loosely grouped in three areas: simplification of spacecraft or mission design; elimination of the reliance on advanced, immature technologies; and increased scientific capabilities."

"With the advent of the Ares $V$, the challenge for program managers will be to temper the appetites of scientists who will clearly recognize the dramatic scientific benefits enabled by the launch system. There will need to be an enforced paradigm shift where cost, rather than launch system capability, is the design limiter. " 